\title{
Priming enables a NEK7-independent route of NLRP3 activation
}

Niklas A. Schmacke ${ }^{1,5}$, Moritz M. Gaidt ${ }^{1,3,5}$, Inga Szymanska ${ }^{1}$, Fionan O’Duill ${ }^{1}$, Che A. Stafford ${ }^{1}$,

Dhruv Chauhan ${ }^{1}$, Adrian L. Fröhlich ${ }^{1}$, Dennis Nagl ${ }^{1}$, Francesca Pinci ${ }^{1}$, Jonathan L. Schmid$\operatorname{Burgk}^{1,4}$, and Veit Hornung ${ }^{1,2, *}$

1 Gene Center and Department of Biochemistry, Ludwig-Maximilians-Universität München, Munich, Germany

2 Center for Integrated Protein Science (CiPSM), Ludwig-Maximilians-Universität München, Munich, Germany

3 Current address: Department of Molecular \& Cell Biology, and Cancer Research Laboratory, University of California, Berkeley, CA, USA

4 Current address: Broad Institute of MIT and Harvard, Cambridge, Massachusetts, USA

5 These authors contributed equally

\section{* Correspondence:}

Veit Hornung (hornung@genzentrum.lmu.de) 


\begin{abstract}
The NLRP3 inflammasome plays a central role in antimicrobial defense, as well as in sterile inflammatory conditions. NLRP3 activity is governed by two independent signals. The first signal primes NLRP3, allowing it to respond to its activation signal. In the murine system, the mitotic spindle kinase NEK7 has been identified as a crucial factor in relaying the activation signal to NLRP3. Here we show that the requirement for NEK7 can be bypassed by TAK1-dependent post-translational priming. Under pro-inflammatory conditions that activate TAK1, NEK7 was dispensable for NLRP3 inflammasome formation in human and murine cells. Intriguingly, dissecting the NEK7 requirement in iPSC-derived primary human macrophages revealed that this NEK7-independent mechanism constitutes the predominant NLRP3 priming pathway in these cells. In summary, our results suggest that NEK7 functions as an NLRP3 priming - rather than activation - factor that can work in synergy or redundancy with other priming pathways to accelerate inflammasome activation.
\end{abstract}




\section{INTRODUCTION}

Cells of the innate immune system employ a repertoire of so-called pattern recognition receptors (PRRs) to discriminate self from non-self. Engagement of these PRRs triggers a broad array of effector functions that are geared towards eliminating a microbial threat. The inflammasome pathway constitutes a special class of this PRR system that is signified by the activation of the cysteine protease caspase-1 in a large supramolecular protein complex (Broz and Dixit, 2016). Activation of caspase- 1 causes maturation of pro-inflammatory cytokines, most prominently IL-1 $\beta$ (Dinarello, 2018), as well as the induction of a special type of cell death, known as pyroptosis (Vande Walle and Lamkanfi, 2016). Among several inflammasome sensors, NLRP3 plays a pivotal role in antimicrobial defense as well as sterile inflammatory diseases (Patel et al., 2017). This is owed to the fact that NLRP3 is a highly sensitive, yet non-specific PRR. In this regard, NLRP3 has been shown to respond to the perturbation of cellular homeostasis by a broad array of diverse stimuli, rather than being activated by a specific microbe-derived molecule (Swanson et al., 2019). $\mathrm{K}^{+}$efflux from the cytosol has been identified as a common denominator of many NLRP3 triggers (Muñoz-Planillo et al., 2013). In this function several types of lytic cell death have been shown to result in secondary engagement of the NLRP3 inflammasome pathway (Gaidt and Hornung, 2018). However, $\mathrm{K}^{+}$-efflux independent NLRP3 stimuli have also been described (Gaidt et al., 2016; Groß et al., 2016) and a recent report has identified dispersal of the trans-Golgi network (TGN) to be a common denominator of both potassium dependent- and independent NLRP3 triggers (Chen and Chen, 2018).

Unlike other inflammasome sensors, NLRP3 critically depends on the engagement of a priming step (Hornung and Latz, 2010). This priming signal can be provided by different types of receptors, typically PRRs that are able to trigger NF-kB activation. Lipopolysaccharide (LPS) activating TLR4 is commonly used to provide a priming signal preceding the actual NLRP3 activation step. 
Initially, the necessity of priming had been ascribed to the fact that NLRP3 is expressed at limiting levels in murine macrophages. In this respect it has been shown that NF-kB activating stimuli drive the expression of Nlrp3, thereby facilitating its activation (Bauernfeind et al., 2009; Kahlenberg et al., 2005). In line with these findings, inhibition of transcription blocks this mode of NLRP3 priming, whereas transgenic expression of NLRP3 bypasses the requirement of transcriptional priming (Bauernfeind et al., 2009; Kahlenberg et al., 2005). Extending this concept, NLRP3 can also be primed non-transcriptionally, e.g. by a short pulse of LPS treatment (Bauernfeind et al., 2016; Juliana et al., 2012; Lin et al., 2014). These modes of priming have been shown to depend on a variety of posttranslational modifications of NLRP3, including phosphorylation, dephosphorylation, de-ubiquitination, and de-sumoylation (Barry et al., 2018; Shim and Lee, 2018). Although being mechanistically unrelated, these events are commonly referred to as posttranslational priming and indicate that many cells already express sufficient amounts of NLRP3 to activate the inflammasome under steady-state conditions.

Despite considerable insight into pathways that mediate NLRP3 priming, the activation step of the NLRP3 inflammasome remained uncharacterized. In this regard, three reports have recently identified the mitotic spindle kinase NEK7 as a critical cofactor in NLRP3 activation in murine cells (He et al., 2016b; Schmid-Burgk et al., 2015; Shi et al., 2016). Notably, this role of NEK7 is distinct from its function in the cell cycle, as its kinase activity is not required for NLRP3 activation (He et al., 2016b; Shi et al., 2016). NEK7 has been suggested to interact with NLRP3 in a $\mathrm{K}^{+}$-efflux dependent manner, and deletion of NEK7 does not affect transcriptional NLRP3 priming (He et al., 2016b; Shi et al., 2016). This has led to the conclusion that NEK7 is involved in NLRP3 activation downstream of $\mathrm{K}^{+}$-efflux (He et al., 2016a). Of note, studies identifying NEK7 as an indispensable factor for NLRP3 activation have mainly been conducted in murine models. Here, we report that reductionist genetic dissection of NLRP3 signaling in human cells revealed a new 
pathway of NLRP3 activation that depends on post-translational modification and enables NLRP3 inflammasome activation independently of NEK 7.

\section{RESULTS}

\section{Human myeloid cell lines activate NLRP3 in the absence of NEK7}

To investigate whether human cells also required NEK7 for NLRP3 activation we made use of the BLaER1 transdifferentiation system that we have previously adopted to study innate immune sensing (Gaidt et al., 2018; Rapino et al., 2013). We subjected $N E K 7^{-/-}$BLaER1 cells to four hours of LPS priming and subsequently stimulated these cells with Nigericin (NLRP3) or Needle Tox (NAIP/NLRC4). As expected, NEK7-deficiency showed no impact on NAIP/NLRC4 inflammasome activation, as assessed by IL-1 $\beta$ maturation (Fig. 1A) or LDH release (Fig. 1B). Surprisingly, $N E K 7^{-/-}$cells also showed no impairment of their NLRP3 inflammasome response (Fig. 1A, B). NEK6 is a close homologue of NEK7, sharing more than $80 \%$ sequence identity. To address whether NEK6 was functionally redundant with NEK7 for NLRP3 activation in human cells, we generated cells deficient for both NEK6 and NEK7. Similar to NEK7-deficient cells, $N E K 6^{-/}, N E K 7^{-/-}$BLaER1 cells displayed unimpaired activation of the NLRP3 inflammasome (Fig. 1A, B). As expected, $N L R P 3^{-/-}$cells showed no response to Nigericin stimulation, while they remained responsive to NAIP/NLRC4 inflammasome activation. In line with these observations, caspase-1 maturation upon Nigericin treatment also proceeded independently of NEK7 (Fig. 1C). To investigate if Nigericin stimulation still activated the NLRP3 inflammasome via potassium efflux in absence of NEK7, we firstly utilized the NLRP3-specific inhibitor MCC950 (Coll et al., 2015). Pretreatment with MCC950 blunted inflammasome activation in wildtype, $N E K 7^{-/-}$and $N E K 6^{--}, N E K 7^{-/-}$cells stimulated with Nigericin, while it left the NAIP/NLRC4 inflammasome intact (Fig. S1A-C). Secondly, preventing $\mathrm{K}^{+}$efflux by increased extracellular $\mathrm{K}^{+}$concentration 
was still able to block NLRP3 but not NAIP/NLRC4 signaling in absence of NEK7 (Fig. 1D and S1D), indicating that Nigericin still relied on inducing potassium efflux to trigger NLRP3 inflammasome activation. Finally, we sought to validate the observation of NEK7-independent NLRP3 activation in a different cell culture model and thus turned to THP-1 cells. Analogous to the results obtained in BLaER1 cells, THP-1 cells deficient in NEK7 showed no attenuation of Nigericin-triggered inflammasome activation, whereas $N L R P 3^{-/-} \mathrm{THP}-1$ cells were completely defective (Fig. 1E-G). Altogether, these results indicated that NEK7 and also NEK6 are not required for NLRP3 activation in human myeloid cell lines.

\section{TAK1-priming bypasses NEK7 during NLRP3 inflammasome activation}

The observation that human BLaER1 and THP-1 cells can activate NLRP3 independently of NEK7 suggests that another signaling event can compensate for NEK7. We wondered whether this compensatory signaling entity also existed in murine cells. To circumvent any effect of transcriptional NLRP3 priming, we addressed this question in murine macrophages that constitutively express NLRP3 (Franklin et al., 2014). As previously shown (Schmid-Burgk et al., 2015), Nigericin-mediated inflammasome stimulation did not require TLR-priming and was completely dependent on NEK7 under these conditions (Fig. 2A-C). However, concomitant stimulation with LPS enabled NEK7-independent NLRP3 inflammasome activation in these cells, suggesting that LPS-priming can also bypass the requirement of NEK7 in murine cells (Fig. 2AC). Analogous results were obtained with R848 or Pam3CSK4 instead of LPS (Fig. S2A-D), and when ATP was used to activate the NLRP3 inflammasome (Fig. 2B). Further, NEK7-independent inflammasome activation in mouse cells was confirmed to drive caspase-1 maturation by immunoblot (Fig. 2C). Of note, simultaneous LPS treatment also enhanced NEK7-dependent NLRP3 inflammasome activation, especially when assessing short stimulation periods (Fig. S2E, 
F). In light of the constitutive Nlrp3 expression that renders these cells insensitive to transcriptional priming of NLRP3 these results suggest that LPS primes NLRP3 post-translationally to allow NEK7-independent activation. In line with this notion, the NEK7-bypass effect was not affected by treatment with the translation-inhibitor cycloheximide (Fig. 2D, S2G). To elucidate the signaling cascade of NEK7-independent post-translational priming, we genetically perturbed TLR4 and its downstream signaling adaptors TRIF (Ticam1) and Myd88 on either wt or Nek7-/backgrounds in these cells. Ticam $1^{-/-}$and $\mathrm{Myd} 88^{-/-}$cells displayed a selective lack of antiviral (IP10) and pro-inflammatory (TNF) gene expression, whereas TLR4 deficiency abrogated LPSdependent cytokine production altogether (Fig. 2E). LPS-dependent post-translational NLRP3priming was dependent on TLR4, yet redundantly employed MyD88 and TRIF. Consequently, only the deletion of both MyD88 and TRIF phenocopied the TLR4 knockout and fully abrogated NEK7-independent NLRP3 activation (Fig. 2E). Since both these pathways converge at the level of the TAK1 complex, we next sought to investigate the role of TAK1 (Map3k7) activity. Since Map $3 k^{-/-}$murine macrophages were not viable, we instead turned to the small molecule inhibitor Takinib. As expected, macrophages treated with Takinib displayed markedly, but not completely, reduced TNF responses upon LPS treatment (Fig. 2F). Stimulating these cells with Nigericin alone only showed a NLRP3-dependent inflammasome response that was completely NEK7-dependent, while inhibiting TAK1 exerted no effect on this response. Conversely, stimulating these cells with LPS + Nigericin uncovered NEK7-independent NLRP3 inflammasome activation, whereas TAK1 inhibition blocked this effect to the same extent it blocked TNF production (Fig. 2F). Taken together, these data establish that post-translational LPS-priming employs TAK1 to alleviate the requirement for NEK7 in NLRP3 inflammasome activation. Moreover, these findings also indicate that TAK1 kinase activity is required for NEK7 independent PTM priming. 


\section{Human NEK7 can be a cofactor for NLRP3}

Turning back to the human innate immune system, we wished to explore whether human myeloid cells activated the NLRP3 inflammasome in the absence of NEK7 due to a species-specific difference in NEK 7 or NLRP3 themselves. Immunoprecipitating NLRP3 in THP-1 cells, we found NEK7 to associate with NLRP3 in a constitutive manner, independently of $\mathrm{K}^{+}$efflux (Figure $3 \mathrm{~A}$, S3A). Since these results established that NEK7 was in principle capable of interacting with human NLRP3, we wondered whether hNEK7 had the ability to activate hNLRP3. To address this question, we reconstituted the NLRP3 inflammasome in $N E K 7^{-/-}$HEK-293T cells with human and murine NLRP3 and NEK7 orthologues (Fig. 3B). These experiments showed that human NEK7 can enhance the activation of both murine and human NLRP3 to a similar extent as murine NEK7

(Fig. 3B, C and S3B, C). These results suggested that although NEK7 is able to participate in hNLRP3 activation, human myeloid cell lines do not rely on NEK7 when forming an NLRP3 inflammasome. Corroborating this, human cells could also activate transgenic mNLRP3 in the absence of NEK7 (Fig. 3D, E). This indicated that it is not a species-specific feature of the NEK7 or NLRP3 molecules themselves that determines whether NLRP3 activation can proceed in the absence of NEK7. Instead, human myeloid cell lines rely by default on a NEK7-independent NLRP3 activation pathway. Based on our observations in murine macrophages that TAK1 activation could bypass NEK7 requirement, we reasoned that BLaER1 cells may employ this pathway by default. Indeed, NLRP3 activation was fully abrogated in TAK1-deficient $\left(M A P 3 K 7^{-/}\right)$ BLaER1 cells, while NAIP/NLRC4 inflammasome activation remained unaffected (Fig. 3F, G). Importantly TAK1 was not required for transcriptional priming of NLRP3 in BLaER1 cells since NLRP3 expression was fully intact in $M A P 3 K 7^{-/-}$cells (Fig. S3D). Moreover, blocking de novo gene expression using cycloheximide did not impact on NLRP3 inflammasome activation in BLaER1 cells (Fig. S3E). As such, the complete defect of these cells in NLRP3 inflammasome 
activation suggests that BLaER1 cells are not capable of NEK7-dependent NLRP3 activation. Taken together, these data establish that human NEK7 is able to participate in NLRP3 inflammasome activation but that human myeloid cell lines employ TAK1 to drive posttranslational priming of NLRP3 instead.

\section{NEK7 accelerates PTM-primed NLRP3 inflammasome activation in human iPS-Macs}

Finally, we wanted to address what role NEK7 has in NLRP3 inflammasome activation in primary human macrophages. To this end we adopted a recently described in vitro differentiation protocol, in which human iPS cells are differentiated into macrophages (hiPS-Macs) (Takata et al., 2017). hiPS-Macs were fully capable of inflammasome activation. Stimulating LPS-primed hiPS-Macs with Nigericin or Needle-Toxin, we observed pyroptosis (LDH release) accompanied by the release of IL-1 $\beta$ and IL-18 (Fig. 4A). Of note, both cytokine- and LDH release in response to Nigericin, but not Needle Tox, were sensitive to treatment with the NLRP3 inhibitor MCC950 (Fig. 4A). To investigate the role of NEK7 in NLRP3 inflammasome activation in hiPS-Macs, we generated $N E K 7^{-/-}$iPS cell clones via CRISPR/Cas9 genome editing (Figure 4B). NEK7 deficiency neither impacted on macrophage differentiation nor did it affect NLRP3 expression levels (Fig. 4C). Following differentiation, we stimulated hiPS-Macs with different types of inflammasome stimuli. As readouts for inflammasome activation, we focused on pyroptosis and IL-18 release. IL-1 $\beta$ release could only be studied in cells subjected to prolonged LPS treatment, consistent with the fact that it needs to be induced de novo, similar to other pro-inflammatory cytokines such as IL-6 (Fig. S4A, B). NEK7 dependency was only observed when hiPS-Macs were stimulated with LPS and Nigericin for one hour (Fig. 4D, purple bars), while after four hours of stimulation NLRP3 inflammasome activity was mostly NEK7-independent (Fig. 4D, red bars). Moreover, prolonged LPS (4 hr) treatment followed by Nigericin $(2 \mathrm{hr})$ stimulation was also largely NEK7 independent 
(Fig. 4D, blue bars). Altogether, these experiments demonstrated that human hiPS-Macs employ NEK7-independent and -dependent modes of NLRP3 activation. Analogous to murine macrophages, concomitant LPS and Nigericin stimulation displays NEK7-dependency at an early time point, while NEK7 is redundant at later time points following NLRP3 activation. After prolonged LPS-treatment, a priming condition typically used for murine macrophages to study IL$1 \beta$ maturation, a partial NEK7 dependence is observed (Fig. 4E).

\section{DISCUSSION}

It is generally accepted that NLRP3 activation requires two signals. A first signal functions to prime NLRP3 to reach a state that allows it to be activated by a second signal - the actual activation signal. NEK7 has been shown to be an essential cofactor of NLRP3 activation and it has been suggested that NEK7 facilitates inflammasome formation by mediating recognition of the second signal. Studying the role of NEK7 in human myeloid cell lines, we made the unexpected discovery that NLRP3 activation can be fully operational in the absence of NEK7. By genetically dissecting NLRP3 inflammasome signaling we uncovered that these cells employ a NEK7-independent signaling cascade instead that drives TAK1-dependent, post-translational priming of NLRP3. While this TAK1-dependent priming signal is the default pathway by which these human myeloid cell lines engage the NLRP3 inflammasome, murine macrophages predominantly rely on NEK7 for NLRP3 priming. However, they can bypass NEK7 and switch to TAK1-dependent priming under certain stimulatory conditions. This NEK7-independency in human myeloid cells could not be attributed to species-specific constitutions of the NEK7 or NLRP3 molecules themselves. As such, immunoprecipitation and reconstitution experiments showed that human NEK7 interacted with human NLRP3 and that NEK7 was able to facilitate NLRP3 activity. In line with this notion, primary human macrophages also employ NEK7 to activate the NLRP3 inflammasome, yet this 
requires LPS priming and is only observed at early timepoints, when their default TAK1 posttranslational priming mechanism is not yet operational. Indeed, in these cells after prolonged LPSpriming the importance of NEK7-dependent priming declines when the other priming cascade becomes available. Altogether, this study establishes NEK7 as a priming rather than an activation signal. Moreover, in its capacity as a priming factor NEK7 does not constitute an absolute requirement for NLRP3 inflammasome activation. Instead, a priming signal emanating from TAK1 can fully compensate for NEK7. Intriguingly, this signal supersedes NEK7 requirement in human myeloid cell lines and also represents the dominant priming entity in primary human macrophages.

Ever since its first description in 2001, NLRP3 has attracted much attention as a key driver of antimicrobial and sterile inflammation (Gaidt and Hornung, 2018). Nonetheless, despite being in the focus for almost two decades the molecular mechanism of NLRP3 activation has remained obscure. The two-step model of inflammasome activation predates the discovery of NLRP3 and inflammasomes altogether, originating from the notion that both a pro-inflammatory and a celldeath inducing signal are required to release mature IL-1 $\beta$ from murine bone marrow derived macrophages (Hogquist et al., 1991). In retrospect, these early studies had assessed NLRP3 inflammasome activation employing a $\mathrm{K}^{+}$efflux inducing trigger. Subsequent studies revealed that the pro-inflammatory signal indeed serves two independent functions in the context of NLRP3 inflammasome activation. While this signal is critically required to induce pro-IL-1 $\beta$ expression, it is also necessary to render NLRP3 activatable in the first place. This became apparent when studying the maturation of caspase-1, the expression of which is independent of a proinflammatory signal, as a proxy of NLRP3 inflammasome activation. Here it was revealed that unprimed macrophages did not mature caspase-1 upon $\mathrm{K}^{+}$efflux inducing stimuli (Kahlenberg et al., 2005; Mariathasan et al., 2004), but that additional priming by a proinflammatory signal was required to 
facilitate this step. Of note, this unique requirement of NLRP3 priming by a pro-inflammatory signal (referred to as signal 1 or priming in this manuscript) must not be confused with the signal that induces pro-IL-1 $\beta$ expression. Indeed, while both signals can be provided by the same PRR, they can also be separated, and the pro-IL-1 $\beta$ inducing stimulus is not necessary for NLRP3 inflammasome activation.

Although the two-step activation model constitutes an important conceptual framework for NLRP3 activation, it has proven to be an enormous conundrum because it is not trivial to allocate signaling events upstream of NLRP3 to either priming or activation. The fact that several NLRP3 priming pathways have been described (Groslambert and Py, 2018) is likely attributable to the fact that stimulus, cell type, species and also temporal aspects play an important role in this context. We conceptualize that priming serves the function to increase the pool of NLRP3 molecules that are able to respond to an activating stimulus, or to lower the activation threshold of individual NLRP3 molecules. In this regard, we would interpret the existence of multiple redundant NLRP3 priming pathways as the possibility to integrate diverse pro-inflammatory inputs to achieve this activatable state. In fact, we consider this pleiotropy to be a key trait of priming - but not activation pathways. Based on the redundancy between TAK1 and NEK7 in facilitating NLRP3 inflammasome activation, we conclude that NEK7 serves as a priming factor of the NLRP3 inflammasome. In line with this notion, recent structural evidence suggests that NEK7 functions to stabilize individual NLRP3 molecules in a semi-open, but not fully active conformation (Sharif et al., 2019). Conceivably, priming-related post-translational modifications might function in a similar modus operandi and are thus redundant with NEK7, as observed in mouse macrophages, or synergistic, as observed in primary human macrophages. 
NEK7 holds a unique position amongst NLRP3 priming pathways in that it is constitutively expressed and apparently uncoupled from upstream signals in its pro-inflammatory capacity. In this regard, it has been suggested that NEK7 is employed for NLRP3 activation in order to avoid inflammasome formation during mitosis, when NEK7 is not available (Shi et al., 2016). Indeed, it has been speculated that the cellular perturbation immediately upstream of NLRP3 commonly occurs during mitosis and thus the dependency on NEK7 prevents inadvertent inflammasome activation during cell division (Sharif et al., 2019). However, the here-uncovered redundancy of NEK7 priming with other cell cycle-independent priming pathways (e.g. TAK1) advocate against a specific de-coupling of NLRP3 inflammasome activation and proliferation. This is also in line with the fact that many NLRP3 inflammasome-competent cells of the innate immune system are indeed postmitotic. As such, despite detailed mechanistic insight into how NEK7 can accelerate NLRP3 inflammasome activation, the physiological role of NEK7 remains to be determined.

Our data suggest that TAK1-dependent signaling constitutes the predominant NLRP3 priming modality in human myeloid cells. Intriguingly, a previous study exploring kinase inhibitors in the context of inflammasome signaling had also identified TAK1 kinase activity as an important facilitator of NLRP3 inflammasome activation (Gong et al., 2010). While these data would argue for TAK1 kinase activity as a potential drug target in the NLRP3 inflammasome pathway, it has to be noted that prolonged inhibition of TAK1 can result in the induction of lytic cell death in the context of pro-inflammatory signals (Malireddi et al., 2018). This, in turn, can lead to secondary activation of the NLRP3 inflammasome due to the perturbation of membrane integrity and associated $\mathrm{K}^{+}$efflux. Consequently, directly targeting NLRP3, or the TAK1-dependent conversion of NLRP3 into an activatable state, would constitute a safer pharmacological approach towards inhibition of NLRP3. 


\section{MATERIALS \& METHODS}

\section{BLaER1 cell culture}

BLaER1 cells (female) were cultivated in RPMI supplemented with $10 \%$ FCS, 1 mM Pyruvate, $100 \mathrm{U} / \mathrm{mL}$ Penicillin and $100 \mu \mathrm{g} / \mathrm{mL}$ Streptomycin at $37{ }^{\circ} \mathrm{C}$ and $5 \% \mathrm{CO}_{2}$. BLaER1 cells were differentiated in Medium containing $10 \mathrm{ng} / \mathrm{mL}$ hrIL-3, $10 \mathrm{ng} / \mathrm{mL}$ hrCSF-1 (M-CSF) and 100nM $\beta$ Estradiol for 5-6 days. In the course of these studies, we serendipitously identified that BLaER1 cells express transcripts of SMRV (Squirrel monkey retrovirus) and subsequent experiments confirmed that BLaER1 cells harbor the SMRV proviral genome. Testing early passages of BLaER1 cells by Dr. Thomas Graf (personal communication) confirmed that the parental BLaER1 cell line (Rapino et al., 2013) is positive for SMRV. Of note, extensive characterization of BLaER1 monocytes in comparison to other human myeloid cells has not provided any indication that SMRV positivity would impact on the functionality of these cells as myeloid cells. Samples of other cell lines used in this work were confirmed to be free of SMRV by PCR.

\section{THP-1 cell culture}

THP-1 cells (male) were obtained from ATCC and cultivated in RPMI supplemented with $10 \%$ FCS, $1 \mathrm{mM}$ Pyruvate, $100 \mathrm{U} / \mathrm{mL}$ Penicillin and $100 \mu \mathrm{g} / \mathrm{mL}$ Streptomycin at $37{ }^{\circ} \mathrm{C}$ and $5 \% \mathrm{CO}_{2}$. THP-1 cells were differentiated by adding $100 \mathrm{ng} / \mathrm{ml}$ PMA to the medium for $18 \mathrm{hr}$, rinsed off with ice-cold PBS and replated for experiments.

\section{hiPSC, hiPS-Macs cell culture}

Human induced pluripotent stem cells (hiPSCs) were kindly provided by Adam O’Neill and Magdalena Götz (Camargo Ortega et al., 2019). hiPSCs were cultivated on Geltrex-coated plates in complete mTeSR1 Medium at $37{ }^{\circ} \mathrm{C}$ and $5 \% \mathrm{CO}_{2}$ and detached for passaging using $1.5 \mathrm{~mL}$ 
Accutase for 5 minutes at $37^{\circ} \mathrm{C}$ after a PBS wash. After passaging, cells were cultivated in the presence of $5 \mu \mathrm{M}$ ROCK-Inhibitor overnight.

\section{Murine Macrophage cell culture}

Murine Macrophages were cultivated in DMEM supplemented with $10 \%$ FCS, 1 mM Pyruvate $100 \mathrm{U} / \mathrm{mL}$ Penicillin and $100 \mu \mathrm{g} / \mathrm{mL}$ Streptomycin at $37^{\circ} \mathrm{C}$ and $5 \% \mathrm{CO}_{2} . \mathrm{mM \Phi}$ were detached for passaging with $0.05 \%$ Trypsin at $37^{\circ}$ for 15 minutes after one PBS wash and then rinsed off with DMEM.

\section{HEK-293T cell culture}

HEK-293T cells were cultivated in DMEM with 10 \% FCS, 1 mM Pyruvate, 100 U/mL Penicillin and $100 \mu \mathrm{g} / \mathrm{mL}$ Streptomycin at $37^{\circ} \mathrm{C}$ and $5 \% \mathrm{CO}_{2}$. For passaging, cells were washed with PBS once and then incubated with $0.05 \%$ Trypsin at $37^{\circ}$ for 5 minutes. Cells were then rinsed off with DMEM.

\section{ASC pyroptosome imaging}

ASC pyroptosomes in transiently transfected HEK-293T cells were imaged $24 \mathrm{hr}$ after Transfection on a Leica Hi8 epifluorescence microscope using 10x magnification. Specks were quantified with CellProfiler (Carpenter et al., 2006).

\section{Differentiation of hiPSCs into hiPS-Macs}

Differentiation into iPS-Macs was achieved as described previously (Takata et al., 2017). Briefly, 150.000 hiPSC were plated into a one well of a Geltrex-coated 6well plate and differentiated in StemPro base medium with StemPro Supplement, $200 \mu \mathrm{g} / \mathrm{mL}$ Human Transferrin, $2 \mathrm{mM}$ 
Glutamine, $0.45 \mathrm{mM}$ MTG and $0.5 \mathrm{mM}$ Ascorbic Acid (= StemPro medium, ascorbic acid was added just before use) by stimulation with $50 \mathrm{ng} / \mathrm{mL}$ VEGF, $5 \mathrm{ng} / \mathrm{mL}$ BMP-4 and $2 \mathrm{mM}$ CHIR99021 at $5 \%$ oxygen for two days, followed by two days of stimulation with $50 \mathrm{ng} / \mathrm{mL}$ VEGF, $5 \mathrm{ng} / \mathrm{mL}$ BMP-4 and $20 \mathrm{ng} / \mathrm{mL}$ FGF2. From day four, StemPro medium was supplemented with $15 \mathrm{ng} / \mathrm{mL}$ VEGF and $5 \mathrm{ng} / \mathrm{mL}$ FGF2. Starting at day six, $10 \mathrm{ng} / \mathrm{mL}$ VEGF, $10 \mathrm{ng} / \mathrm{mL}$ FGF2, $50 \mathrm{ng} / \mathrm{mL}$ SCF, $30 \mathrm{ng} / \mathrm{mL}$ DKK-1, $10 \mathrm{ng} / \mathrm{mL}$ IL-6 and $20 \mathrm{ng} / \mathrm{mL}$ IL-3 were added to StemPro medium until day ten. From day eight, cells were cultivated under normoxic conditions. From day twelve, $10 \mathrm{ng} / \mathrm{mL}$ FGF2, $50 \mathrm{ng} / \mathrm{mL} \mathrm{SCF}, 10 \mathrm{ng} / \mathrm{mL}$ IL-6 and $20 \mathrm{ng} / \mathrm{mL}$ IL-3 were added to StemPro medium. Starting at day sixteen, cells were cultivated in $75 \%$ IMDM with $25 \%$ F12 supplement, N2 supplement, B-27 supplement, $0.05 \%$ BSA and $100 \mathrm{U} / \mathrm{mL}$ Penicillin and $100 \mu \mathrm{g} / \mathrm{mL}$ Streptomycin (= SF-Diff Medium) supplemented with $50 \mathrm{ng} / \mathrm{mL}$ rhCSF-1 (M-CSF) at least until day 28. Culture medium was exchanged as necessary, but at least every two days. After differentiation, hiPS-Macs were carefully harvested from the supernatant, spun down and replated in RPMI medium with $10 \%$ FCS, $1 \mathrm{mM}$ Pyruvate, $100 \mathrm{U} / \mathrm{mL}$ Penicillin and $100 \mu \mathrm{g} / \mathrm{mL}$ Streptomycin for experiments.

\section{Immunoblotting}

Cells were lysed at approximately $5 \mathrm{Mio} / \mathrm{mL}$ in 1x Lämmli Buffer and boiled for 5 minutes at 95 ${ }^{\circ} \mathrm{C}$. For precipitation of total protein from supernatants, stimulations were done in medium containing 3\% FCS. Precipitation of total protein from supernatants was achieved by combining $700 \mu \mathrm{L}$ of supernatant with $700 \mu \mathrm{L} \mathrm{MeOH}$ and $150 \mu \mathrm{L}$ of $\mathrm{CHCl}_{3}$. Samples were spun down at $20.000 \mathrm{~g}$ for 20 minutes, and the upper phase was discarded. Again, $700 \mu \mathrm{L} \mathrm{MeOH}$ were added and samples were centrifuged at $20.000 \mathrm{~g}$ for 20 minutes. The pellet was then dried and resuspended in $100 \mu \mathrm{L} 1 \mathrm{x}$ Lämmli buffer and boiled at $95{ }^{\circ} \mathrm{C}$ for 5 minutes. Samples were run on $12 \%$ SDS- 
PAGE gels at $150 \mathrm{~V}$ for 85 minutes and were subsequently transferred onto a nitrocellulose membrane at $100 \mathrm{~V}$ for 75 minutes at $4{ }^{\circ} \mathrm{C}$. Membranes were then blocked in $5 \%$ milk for $1 \mathrm{hr}$ at room temperature. Primary and secondary antibodies were diluted in 1-5\% milk.

\section{ELISA and LDH assay}

LDH assays were done on supernatants immediately after experiments. Results are presented relative to a lysis control from the same experiment with the values of unstimulated controls subtracted as background. ELISAs were done according to manufacturer's instructions on supernatants stored at $-20^{\circ} \mathrm{C}$.

\section{Stimulation}

NLRP3 was primed as indicated with $1 \mu \mathrm{g} / \mathrm{mL}$ Pam3CSK4 or $200 \mathrm{ng} / \mathrm{mL}$ LPS. NLRP3 was activated with $5 \mathrm{mM}$ ATP for $2 \mathrm{hr}$ or Nigericin at $6.5 \mu \mathrm{M}$ or $10 \mu \mathrm{M}$ as indicated for up to $4 \mathrm{hr}$. To activate the AIM2 inflammasome 400ng HT-DNA were transfected into a 96-well with $0.5 \mu \mathrm{L}$ Lipofectamine in $50 \mu \mathrm{L}$ OptiMEM by incubating OptiMEM and Lipofectamine for 5 minutes followed by 20 minutes of incubation of the Lipofectamine-DNA mix in OptiMEM and dropwise addition of the mix to the cells. The NAIP/NLRC4 inflammasome was activated with $0.25 \mu \mathrm{g} / \mathrm{mL}$ protective antigen (pA) and $0.025 \mu \mathrm{g} / \mathrm{mL}$ needle tox (LF-YscF) for $2 \mathrm{hr}$.

\section{Inhibition of translation}

For murine macrophages, cycloheximide ( $\mathrm{CHX}$ ) was added to the medium 30 min before stimulation to a final concentration of $10 \mu \mathrm{g} / \mathrm{mL}$. For BLaER 1 cells, CHX was added to the medium simultaneously with LPS at the indicated concentrations in the range of $1-10 \mu \mathrm{g} / \mathrm{mL}$. 


\section{Doxycyclin-inducible gene expression}

In BLaER 1 cells transduced with pLI-Puro derived vectors, gene expression was induced by adding Medium to a final concentration of $1 \mu \mathrm{g} / \mathrm{mL}$ doxycyclin for the last $24 \mathrm{hr}$ of differentiation.

\section{Pharmacological Inhibition of TAK1 and NLRP3}

Takinib was added to the medium to a final $50 \mu \mathrm{M}$ concentration $1 \mathrm{hr}$ before stimulation. MCC950 was added to the medium $1 \mathrm{hr}$ before priming to a final concentration of $10 \mu \mathrm{M}$.

\section{Inhibition of $\mathrm{K}^{+}$-efflux}

Potassium chloride was added to the medium together with the priming stimulus to the indicated final concentrations. The overall osmolarity of the medium was kept constant over all conditions.

\section{Transient Transfection of HEK-293T cells}

HEK-293T cells were transiently transfected with 400ng Plasmid DNA in $50 \mu \mathrm{L}$ OptiMEM with $1 \mu \mathrm{L}$ GeneJuice by incubating GeneJuice with OptiMEM for 5 minutes followed by 15 minutes of incubation of the DNA-GeneJuice mix in OptiMEM. DNA concentrations were kept constant across all conditions using pBluescript as stuffer DNA.

\section{Plasmid DNA purification}

Plasmid DNA was purified from E.Coli DH5 $\alpha$ using a Thermo HiPure Maxiprep Kit according to manufacturer's instructions.

\section{Preparation of Lentiviral Particles}


Lentiviral particles were prepared according to (Kutner et al., 2009). Briefly, HEK-293T cells were transfected with $20 \mu \mathrm{g}$ transfer plasmid, $15 \mu \mathrm{g}$ pCMV $\Delta 8.91$ packaging plasmid and $6 \mu \mathrm{g}$ pMD2.G VSV-G pseudotyping plasmid dish by diluting the plasmids in $1 \mathrm{~mL} 1 \mathrm{x} \mathrm{HBS}$, adding $50 \mu \mathrm{L} 2.5 \mathrm{M}$ Calcium chloride and gently pipetting the mix onto a $10 \mathrm{~cm}$ dish with approximately 6 Mio. HEK$293 \mathrm{~T}$ cells in fresh medium. After $8 \mathrm{hr}$ the medium was exchanged. Supernatants were harvested $48 \mathrm{hr}$ later, spun down and filtered before being used to transduce target cells. Successfully transduced cells were selected with $2.5-5 \mu \mathrm{g} / \mathrm{mL}$ Puromycin or $10 \mu \mathrm{g} / \mathrm{mL}$ Blasticidin S for $48 \mathrm{hr}$, or FACSorted for Fluorescence markers.

\section{Genome Editing and Overexpression}

sgRNA oligos were designed using CHOPCHOP (Labun et al., 2019) and cloned into expression Plasmids as described previously (Sanjana et al., 2014; Schmid-Burgk et al., 2014). BLaER1 cells were electroporated in OptiMEM with $5 \mu \mathrm{g}$ of plasmids driving expression of Cas 9 and an sgRNA on a BioRad GenePulser XCell as described previously (Schmidt et al., 2015). THP-1 cells and murine macrophages were transduced with lentiviral particles driving expression of Cas9 (LentiCas9-Blast (Sanjana et al., 2014)) or an sgRNA (LentiGUIDE-Puro (Sanjana et al., 2014)). HEK$293 \mathrm{~T}$ cells were transiently transfected with plasmids driving expression of Cas9 or an sgRNA. LentiGuide-Puro (Addgene plasmid \#52963) and LentiCas9-Blast (Addgene plasmid \#52962) were gifts from Feng Zhang.

hiPS cells conditioned to grow as single clones were electroporated with Cas9-crRNA-trRNA complexes (RNPs) targeting NEK7. Grown single clones were duplicated, lysed and out-of-frame editing in NEK7 was analyzed via deep sequencing as described previously (Schmid-Burgk et al., 2014). Several $N E K 7^{-/}$and $N E K 7^{+/+}$clones were expanded and used for experiments. 


\section{STATISTICAL ANALYSIS}

Numbers of independent replicates (n) are reported in the respective figure legends. p-values were calculated based on two-way ANOVAs followed by Sidak's multiple comparisons test for groups containing two elements, or Tukey's test for larger groups. All statistical analyses were done using GraphPad Prism 7. * $\mathrm{p}<0.05, * * \mathrm{p}<0.01, * * * \mathrm{p}<0.001, * * * * \mathrm{p}<0.0001, \mathrm{~ns} \mathrm{p} \geq 0.05$ 


\section{RESOURCES}

\begin{tabular}{|c|c|c|}
\hline REAGENT or RESOURCE & SOURCE & IDENTIFIER \\
\hline \multicolumn{3}{|l|}{ Antibodies } \\
\hline anti-Caspase-1 (p20) (human), mAb (Bally-1) & $\begin{array}{l}\text { AdipoGen, San Diego, } \\
\text { CA }\end{array}$ & $\begin{array}{l}\text { Cat\# AG-20B-0048- } \\
\text { C100 }\end{array}$ \\
\hline anti-Caspase-1 (p20) (mouse), mAb (Casper-1) & AdipoGen & $\begin{array}{l}\text { Cat\# AG-20B-0042- } \\
\text { C100 }\end{array}$ \\
\hline anti-NEK7 & $\begin{array}{l}\text { Abcam, Cambridge, } \\
\text { UK }\end{array}$ & Cat\# ab133514 \\
\hline anti-NLRP3/NALP3, mAb (Cryo-2) & AdipoGen & $\begin{array}{l}\text { Cat\# AG-20B-0014- } \\
\text { C100 }\end{array}$ \\
\hline anti-Human IL-1 beta /IL-1F2 & $\begin{array}{l}\text { R\&D Systems Inc, } \\
\text { Minneapolis, MN }\end{array}$ & Cat\# AF-201-NA \\
\hline \multicolumn{3}{|l|}{ Chemicals, Peptides, and Recombinant Proteins } \\
\hline 1-Thioglycerol (MTG) & $\begin{array}{l}\text { Sigma-Aldrich, St. } \\
\text { Louis, MO }\end{array}$ & Cat\# M6145 \\
\hline Accutase & $\begin{array}{l}\text { Stemcell } \\
\text { Technologies, } \\
\text { Vancouver, Canada }\end{array}$ & Cat\# 07920 \\
\hline Adenosine 5'-triphosphate disodium salt hydrate & Sigma-Aldrich & Cat\# A6419 \\
\hline Ascorbic Acid & Sigma-Aldrich & Cat\# A4544-100G \\
\hline B-27 supplement & $\begin{array}{l}\text { Thermo Fisher } \\
\text { Scientific, Waltham, } \\
\text { MA }\end{array}$ & Cat\# 17504-001 \\
\hline Blasticidin S HCl (10 mg/mL) & $\begin{array}{l}\text { Thermo Fisher } \\
\text { Scientific }\end{array}$ & Cat\# A1113903 \\
\hline$\overline{B S A}$ & $\begin{array}{l}\text { GE Healthcare, } \\
\text { Chicago, IL }\end{array}$ & Cat\# SH30574.01 \\
\hline CHIR99021 & $\begin{array}{l}\text { Miltenyi Biotec, } \\
\text { Bergisch Gladbach, } \\
\text { Germany }\end{array}$ & Cat\# 130-103-926 \\
\hline Cycloheximide & $\begin{array}{l}\text { Carl Roth, Karlsruhe, } \\
\text { Germany }\end{array}$ & Cat\# 8682.1 \\
\hline Doxycycline hyclate & Sigma-Aldrich & Cat\# D9891-1G \\
\hline Geltrex & $\begin{array}{l}\text { Thermo Fisher } \\
\text { Scientific }\end{array}$ & Cat\# A1413302 \\
\hline GeneJuice & $\begin{array}{l}\text { Merck, Darmstadt, } \\
\text { Germany }\end{array}$ & Cat\# 70967-3 \\
\hline Glutamic Acid & $\begin{array}{l}\text { Thermo Fisher } \\
\text { Scientific }\end{array}$ & Cat\# 25030024 \\
\hline Ham's F12 nutrient mix & $\begin{array}{l}\text { Thermo Fisher } \\
\text { Scientific }\end{array}$ & Cat\# 21765029 \\
\hline Herring Testis(HT)-DNA sodium salt & Sigma Aldrich & Cat\# D6898 \\
\hline Human CSF-1 (M-CSF) (iPSC differentiation) & R\&D Systems & Cat\# 216-MC-005 \\
\hline Human Transferrin & $\begin{array}{l}\text { Roche, Basel, } \\
\text { Switzerland }\end{array}$ & $\begin{array}{l}\text { Cat\# 10-652-202- } \\
001\end{array}$ \\
\hline IMDM with GlutaMAX & $\begin{array}{l}\text { Thermo Fisher } \\
\text { Scientific }\end{array}$ & Cat\# 31980022 \\
\hline LF-YscF & This Study & N/A \\
\hline Lipofectamine 2000 Transfection Reagent & $\begin{array}{l}\text { Thermo Fisher } \\
\text { Scientific }\end{array}$ & Cat\# 11668019 \\
\hline
\end{tabular}




\begin{tabular}{|c|c|c|}
\hline LPS-EB Ultrapure & $\begin{array}{l}\text { Invivogen, San Diego, } \\
\text { CA }\end{array}$ & Cat\# tlrl-3pelps \\
\hline MCC950 & Sigma-Aldrich & Cat\# PZ0280 \\
\hline mTeSR1 & Stemcell Technologies & Cat\# 85850 \\
\hline $\mathrm{N}$-2 Supplement & $\begin{array}{l}\text { Thermo Fisher } \\
\text { Scientific }\end{array}$ & Cat\# 17502048 \\
\hline Nigericin sodium salt & Sigma-Aldrich & Cat\# N7143 \\
\hline Pam3CSK4 & Invivogen & Cat\# tlrl-pms \\
\hline Phorbol 12-myristate 13-acetate & $\begin{array}{l}\text { ENZO Life Sciences, } \\
\text { Farmingdale, NY }\end{array}$ & $\begin{array}{l}\text { Cat\# BML-PE160- } \\
\text { Cat\# } 0005\end{array}$ \\
\hline Protective antigen $(\mathrm{pA})$ & $\begin{array}{l}\text { Biotrend, Cologne, } \\
\text { Germany }\end{array}$ & Cat\# LL-171E \\
\hline Puromycin Dihydrochlorid & Carl Roth & Cat\# 0240.4 \\
\hline Recombinant Human BMP-4 & R\&D Systems & Cat\# 314-BP-010 \\
\hline $\begin{array}{l}\text { Recombinant Human CSF-1 (M-CSF) (BlaER1 } \\
\text { differentiation) }\end{array}$ & $\begin{array}{l}\text { Recombinantly } \\
\text { produced }\end{array}$ & $\mathrm{N} / \mathrm{A}$ \\
\hline Recombinant Human DKK-1 & R\&D Systems & Cat\# 5439-DK-010 \\
\hline Recombinant Human FGF2 & R\&D Systems & Cat\# 233-FB-025 \\
\hline Recombinant Human IL-3 & R\&D Systems & Cat\# 203-IL-010 \\
\hline Recombinant Human IL-3 (BLaER1 differentiation) & $\begin{array}{l}\text { Recombinantly } \\
\text { produced }\end{array}$ & N/A \\
\hline Recombinant Human IL-6 & R\&D Systems & Cat\# 206-IL-010 \\
\hline Recombinant Human SCF & R\&D Systems & Cat\# 255-SC-010 \\
\hline Recombinant Human VEGF & R\&D Systems & Cat\# 293-VE-010 \\
\hline ROCK Inhibitor Y-27632 & Stemcell Technologies & Cat\# 72302 \\
\hline Stempro-24 SFM & $\begin{array}{l}\text { Thermo Fisher } \\
\text { Scientific }\end{array}$ & Cat\# 10639-011 \\
\hline Takinib & $\begin{array}{l}\text { Selleck Chemicals, } \\
\text { Houston, TX }\end{array}$ & Cat\# S8663 \\
\hline$\beta$-Estradiol & Sigma-Aldrich & Cat\# E8875 \\
\hline \multicolumn{3}{|l|}{ Critical Commercial Assays } \\
\hline Human IL-1 ELISA Set II & $\begin{array}{l}\text { BD Biosciences, San } \\
\text { José, CA }\end{array}$ & Cat\# 557953 \\
\hline Human Total IL-18 DuoSet ELISA & R\&D Systems & Cat\# DY318-05 \\
\hline MiSeq Reagent Kit v2, 300 Cycles & $\begin{array}{l}\text { Illumina, San Diego, } \\
\text { CA }\end{array}$ & Cat\# MS-102-2002 \\
\hline Mouse CXCL10/IP-10/CRG-2 DuoSet ELISA & R\&D Systems & Cat\# DY466 \\
\hline Mouse TNF (Mono/Mono) ELISA Set II & BD Biosciences & Cat\# 558534 \\
\hline OptEIA Human IL-6 ELISA Set & BD Biosciences & Cat\# 555220 \\
\hline OptEIA Mouse IL-1ßeta Elisa Set & BD Biosciences & Cat\# 559603 \\
\hline Pierce LDH Cytotoxicity Assay Kit & $\begin{array}{l}\text { Thermo Fisher } \\
\text { Scientific }\end{array}$ & Cat\# 88954 \\
\hline \multicolumn{3}{|l|}{ Experimental Models: Cell Lines } \\
\hline BLaER1 & (Rapino et al., 2013) & $\mathrm{N} / \mathrm{A}$ \\
\hline HEK-293T & (Cavlar et al., 2013) & $\mathrm{N} / \mathrm{A}$ \\
\hline iPSC & $\begin{array}{l}\text { (Camargo Ortega et } \\
\text { al., 2019) }\end{array}$ & $\mathrm{N} / \mathrm{A}$ \\
\hline Mouse Macrophages, NIrp3, Asc-CFP, Cas9-expressing & (Franklin et al., 2014) & $\mathrm{N} / \mathrm{A}$ \\
\hline THP-1 & ATCC, Manassas, VA & Cat\# TIB-202 \\
\hline
\end{tabular}




\begin{tabular}{|l|l|l|}
\hline \multicolumn{2}{|l|}{ Refer to supplementary Table 2 for sgRNA target sites } & \multicolumn{2}{l|}{} \\
\hline Recombinant DNA & (Sanjana et al., 2014) & N/A \\
\hline LentiCas9-Blast & (Sanjana et al., 2014) & N/A \\
\hline LentiGUIDE-Puro & (Schmidt et al., 2015) & N/A \\
\hline pBabe-U6-sgRNA-Cas9 & This study & N/A \\
\hline pBlast-hNEK7 & This study & N/A \\
\hline pBlast-mNek7 & This study & N/A \\
\hline pLIX-hNLRP3 & This study & N/A \\
\hline pLIX-mNIrp3 & $\begin{array}{l}\text { (Schmid-Burgk et al., } \\
\text { N/A }\end{array}$ & 2014) \\
\hline pLK0.1-sgRNA-CMV-GFP & This study & N/A \\
\hline pRP-Asc-RFP & (Schmidt et al., 2015) & N/A \\
\hline pRZ-CMV-Cas9 & & \\
\hline Software and Algorithms & $\begin{array}{l}\text { (Carpenter et al., } \\
2006)\end{array}$ & https://cellprofiler.org \\
\hline CellProfiler 3.1.5 & (Labun et al., 2019) & $\begin{array}{l}\text { https://chopchop.cbu } \\
\text {.uib.no }\end{array}$ \\
\hline CHOPCHOP & $\begin{array}{l}\text { (Schmid-Burgk et al., } \\
\text { http://www.outknock } \\
\text { er.org }\end{array}$ \\
\hline Outknocker & $\begin{array}{l}\text { GraphPad, San Diego, } \\
\text { CA }\end{array}$ & $\begin{array}{l}\text { https://www.graphpa } \\
\text { d.com/scientific- } \\
\text { software/prism/ }\end{array}$ \\
\hline Prism 7.0 & & \\
\end{tabular}




\section{AUHTOR CONTRIBUTIONS}

Conceptualization N.A.S., M.M.G., F.O., J.L.S.-B. and V.H.; Formal Analysis, Software, Visualization N.A.S.; Investigation N.A.S., M.M.G., I.S., C.A.S., D.C., A.L.F., D.N., F.P. and J.L.S.-B.; Resources V.H.; Writing N.A.S., M.M.G. and V.H. with input from all authors; Funding Acquisition V.H.; Supervision V.H.

\section{ACKNOWLEDGEMENTS}

We kindly thank Andreas Wegerer (Gene Center, LMU) for great technical support, the BioSysM FACS Core Facility (Gene Center, LMU) for cell sorting, Andreas Pichlmair (Technical University of Munich, Munich) for providing the pLIX plasmid, Adam O’Neill and Magdalena Götz (Department of Physiological Genomics, LMU) for providing us with the hiPSCs and helping us set up experiments with these cells, Russell Vance (UC Berkeley, USA) for providing us with the Needle Tox expression plasmid and Manuela Moldt and Karl-Peter Hopfner (Gene Center, LMU) for help producing the Needle Tox protein. This work was supported by grants from the ERC (ERC2014-CoG - 647858 GENESIS) and funded by the Deutsche Forschungsgemeinschaft (DFG, German Research Foundation) - project number 404446805 - TRR 237 to VH.

\section{DECLARATION OF INTERESTS}

V.H. serves on the Scientific Advisory Board of Inflazome Ltd. 


\section{FIGURE LEGENDS}

Figure 1. Human myeloid cell lines activate NLRP3 independently of NEK7

(A, B, C) BLaER1 monocytes of the indicated genotypes were primed with LPS for $4 \mathrm{hr}$ and subsequently stimulated with Nigericin or pA and Needle Tox (LF-YscF). IL-1 $\beta$, IL-6 (A) and LDH release (B) of two clones per genotype are depicted as mean + SEM of three experiments. (C) One representative immunoblot of three independent experiments is shown for caspase-1 release. (D) BLaER1 monocytes of the indicated genotypes were stimulated as in (A) in the presence of up to $60 \mathrm{mM}$ potassium chloride. $\mathrm{LDH}$ release is depicted as mean + SEM of three experiments. (E, F, G) THP-1 cells of the indicated genotypes were primed with Pam3CSK 4 for 4 $\mathrm{hr}$ and subsequently stimulated as in (A). Data are represented as mean $+\mathrm{SEM}$ of the indicated number of $\mathrm{c}=$ clones from one representative experiment of two. Two different $\mathrm{sgRNAs}$ targeting NEK7 are shown. The immunoblot in $(\mathrm{G})$ is one representative of three independent experiments. $* * * * \mathrm{p}<0.0001, * * * \mathrm{p}<0.001, * \mathrm{p}<0.05, \mathrm{~ns} \mathrm{p} \geq 0.05$. See also Figure $\mathrm{S} 1$.

Figure 2. Priming activates TAK1 to bypass NEK7 via a translation-independent mechanism (A-C) Murine macrophages of the indicated genotypes were stimulated with LPS + Nigericin simultaneously for $4 \mathrm{hr}$, with DNA for $28 \mathrm{hr}$ or with LPS + ATP for $2 \mathrm{hr}$. (C) One immunoblot representative of two clones from two independent experiments is shown. (D) $\mathrm{mM} \Phi$ were pretreated with cycloheximide (CHX) for 30 min and stimulated as in A-C. (E) Two mMФ clones per genotype were stimulated as indicated. Cytokine and LDH release of two clones (sub-columns) from three independent experiments (sub-rows) are depicted as heatmaps. (F) $\mathrm{mM} \Phi$ of the indicated genotypes were stimulated as in (A-C) in the presence of Takinib. Bars represent mean 
+ SEM of three independent experiments. $* * * * p<0.0001, * * * \mathrm{p}<0.001, \mathrm{~ns} \mathrm{p} \geq 0.05$. See also Figure S2.

Figure 3. Human NEK7 can be a cofactor for NLRP3

(A) Pam3CSK4-primed THP-1 cells were stimulated with Nigericin for $30 \mathrm{~min}$ and lysates were immunoprecipitated with anti-NEK7 or isotype control. One representative immunoblot of three independent experiments is shown. (B, C) $N E K 7^{-/-}$HEK293T cells were transiently transfected with the indicated plasmids and ASC-RFP specks were imaged $24 \mathrm{hr}$ after transfection. Dots represent technical replicates from one representative of three independent experiments. (D, E) BLaER1 cells expressing doxycyclin-inducible NLRP3 were stimulated as indicated. Data is depicted as mean + SEM of $n=3(D)$ or one representative immunoblot of three (E). (F-G) BLaER1 monocytes of the indicated genotypes were primed with LPS for $4 \mathrm{hr}$ and stimulated as indicated for $2 \mathrm{hr}(\mathrm{F})$ or stimulated with LPS + Nigericin for $1 \mathrm{hr}(\mathrm{G})$. Mean + SEM of three independent experiments. ${ }^{* * *} \mathrm{p}<0.0001, * * * \mathrm{p}<0.001, \mathrm{~ns} \mathrm{p} \geq 0.05$. See also Figure S3 and Table S1.

\section{Figure 4. Priming bypasses NEK7 in Human iPS cell derived macrophages}

(A) HiPS-Macs were primed with LPS for $4 \mathrm{hr}$ and stimulated as indicated for $2 \mathrm{hr}$. Cytokine and LDH release of individual clones differentiated in one batch is depicted. (B) Deep sequencing analysis of genome editing in human iPS cells. (C) Immunoblotting of human hiPS-Macs. (D) Wildtype and $\mathrm{NEK}^{-/-}$hiPS-Macs were stimulated as indicated. Dots represent individual clones from one experiment. $* * * \mathrm{p}<0.0001, * * * \mathrm{p}<0.001,{ }^{*} \mathrm{p}<0.05$, ns $\mathrm{p} \geq 0.05$. (E) Model of NEK7dependent and -independent NLRP3 Priming. PTM: posttranslational modification. See also Figure S4. 


\section{SUPPLEMENTAL FIGURE LEGENDS}

Figure S1 related to Figure 1. Human myeloid cell lines activate NLRP3 independently of NEK7 (A - C) BLaER1 monocytes were stimulated as in A in the presence of $10 \mu \mathrm{M}$ MCC950. IL-1 $\beta$, IL-6 and LDH release are depicted as mean + SEM of three independent experiment. (D) BLaER1 monocytes of the indicated genotypes were primed with $200 \mathrm{ng} / \mathrm{mL}$ LPS for $4 \mathrm{hr}$ and subsequently stimulated with $6.5 \mu \mathrm{M}$ Nigericin or $0.25 \mu \mathrm{g} / \mathrm{mL}$ pA and $0.025 \mu \mathrm{g} / \mathrm{mL}$ Needle Tox (LF-YscF) in the presence of up to $60 \mathrm{mM}$ Potassium Chloride. IL-6 release is depicted as mean + SEM of three independent experiments.

Figure S2 related to Figure 2. Priming activates TAK1 to bypass NEK7 via a translationindependent mechanism

(A) Murine Macrophages of the indicated genotypes were treated with $\mathrm{R} 848+$ Nigericin simultaneously for $4 \mathrm{hr}$. (B) Murine Macrophages of the indicated genotypes were treated with R848 + Nigericin simultaneously for $3 \mathrm{hr}$. (C) Murine Macrophages of the indicated genotypes were treated with Pam3CSK4 (Pam3) + Nigericin simultaneously for $4 \mathrm{hr}$. (D) Murine Macrophages of the indicated genotypes were treated with Pam3CSK4 + Nigericin simultaneously for $3 \mathrm{hr}$. (E) Murine Macrophages of the indicated genotypes were treated with LPS + Nigericin simultaneously for $1 \mathrm{hr}$. (F) Murine Macrophages of the indicated genotypes were stimulated as indicated for up to $4 \mathrm{hr}$. (G) Murine macrophages of the indicated genotypes were pretreated with cycloheximide (CHX) and stimulated with LPS for $2 \mathrm{hr}$. Release of TNF and LDH is depicted as the mean of three independent experiments \pm SEM. Western Blots represent one of two clones from one of three independent experiments. $* * * * \mathrm{p}<0.0001, * * * \mathrm{p}<0.001, * * \mathrm{p}<0.01$. 
Figure S3 related to Figure 3. Human NEK7 can be a cofactor for NLRP3

(A) Dots represent IL-1 $\beta$ release from replicates of the immunoprecipitation in Figure $3 \mathrm{~A}$. Data in red correspond to the replicate shown in Figure 3A. (B) Sample images corresponding to the experiment shown in Figure 3C. Colors of RFP fluorescence images were inverted for visual clarity, scalebars represent $300 \mu \mathrm{m}$. "speck detection" shows automatically detected specks in the area outlined in "RFP". (C) The expression of NEK7, NLRP3 and ASC-RFP was confirmed via immunoblotting $24 \mathrm{hr}$ after transient transfection of HEK-293T cells. Immunoblot is one representative of two independent experiments. (D) TAK1 deficient BLaER1 Monocytes were treated with LPS for $6 \mathrm{hr}$ before lysates were immunoblotted. One representative of three independent experiments is shown. (E) BLaER1 monocytes were primed with LPS and treated with Nigericin or protective antigen and needle tox in the presence of the indicated concentrations of CHX. LDH and IL-6 release are depicted as mean + SEM of three independent experiments.

Figure S4 related to Figure 4. Priming bypasses NEK7 in Human iPS cell derived macrophages (A, B) wt and $N E K 7^{-/-}$hiPS-Macs were stimulated as indicated. Release of IL-1 $\beta$ (A) and IL-6 (B) is depicted as mean + SEM of three independent experiments. 


\section{REFERENCES}

Barry, R., John, S.W., Liccardi, G., Tenev, T., Jaco, I., Chen, C.-H., Choi, J., Kasperkiewicz, P., Fernandes-Alnemri, T., Alnemri, E., et al. (2018). SUMO-mediated regulation of NLRP3 modulates inflammasome activity. Nat Commun 9, 3001.

Bauernfeind, F., Niepmann, S., Knolle, P.A., and Hornung, V. (2016). Aging-Associated TNF Production Primes Inflammasome Activation and NLRP3-Related Metabolic Disturbances. J. Immunol. 197, 2900-2908.

Bauernfeind, F.G., Horvath, G., Stutz, A., Alnemri, E.S., MacDonald, K., Speert, D., FernandesAlnemri, T., Wu, J., Monks, B.G., Fitzgerald, K.A., et al. (2009). Cutting edge: NF-kappaB activating pattern recognition and cytokine receptors license NLRP3 inflammasome activation by regulating NLRP3 expression. J. Immunol. 183, 787-791.

Broz, P., and Dixit, V.M. (2016). Inflammasomes: mechanism of assembly, regulation and signalling. Nature Reviews Immunology 16, 407-420.

Camargo Ortega, G., Falk, S., Johansson, P.A., Peyre, E., Broix, L., Sahu, S.K., Hirst, W., Schlichthaerle, T., De Juan Romero, C., Draganova, K., et al. (2019). The centrosome protein AKNA regulates neurogenesis via microtubule organization. Nature 567, 113-117.

Carpenter, A.E., Jones, T.R., Lamprecht, M.R., Clarke, C., Kang, I.H., Friman, O., Guertin, D.A., Chang, J.H., Lindquist, R.A., Moffat, J., et al. (2006). CellProfiler: image analysis software for identifying and quantifying cell phenotypes. Genome biology 7, R100.

Cavlar, T., Deimling, T., Ablasser, A., Hopfner, K.-P., and Hornung, V. (2013). Species-specific detection of the antiviral small-molecule compound CMA by STING. The EMBO Journal 32, 1440-1450.

Chen, J., and Chen, Z.J. (2018). PtdIns4P on dispersed trans-Golgi network mediates NLRP3 inflammasome activation. Nature 16, 407.

Coll, R.C., Robertson, A.A.B., Chae, J.J., Higgins, S.C., Muñoz-Planillo, R., Inserra, M.C., Vetter, I., Dungan, L.S., Monks, B.G., Stutz, A., et al. (2015). A small-molecule inhibitor of the NLRP3 inflammasome for the treatment of inflammatory diseases. Nature Medicine 21, 248-255.

Dinarello, C.A. (2018). Overview of the IL-1 family in innate inflammation and acquired immunity. Immunological reviews 281, 8-27.

Franklin, B.S., Bossaller, L., De Nardo, D., Ratter, J.M., Stutz, A., Engels, G., Brenker, C., Nordhoff, M., Mirandola, S.R., Al-Amoudi, A., et al. (2014). The adaptor ASC has extracellular and 'prionoid' activities that propagate inflammation. Nat. Immunol. 15, 727-737. 
Gaidt, M.M., Ebert, T.S., Chauhan, D., Schmidt, T., Schmid-Burgk, J.L., Rapino, F., Robertson, A.A.B., Cooper, M.A., Graf, T., and Hornung, V. (2016). Human Monocytes Engage an Alternative Inflammasome Pathway. Immunity 44, 833-846.

Gaidt, M.M., and Hornung, V. (2018). The NLRP3 Inflammasome Renders Cell Death Proinflammatory. J. Mol. Biol. 430, 133-141.

Gaidt, M.M., Rapino, F., Graf, T., and Hornung, V. (2018). Modeling Primary Human Monocytes with the Trans-Differentiation Cell Line BLaER1. Methods in molecular biology (Clifton, N.J.) $1714,57-66$.

Gong, Y.-N., Wang, X., Wang, J., Yang, Z., Li, S., Yang, J., Liu, L., Lei, X., and Shao, F. (2010). Chemical probing reveals insights into the signaling mechanism of inflammasome activation. Cell research 20, 1289-1305.

Groslambert, M., and Py, B.F. (2018). Spotlight on the NLRP3 inflammasome pathway. Journal of inflammation research 11,359-374.

Groß, C.J., Mishra, R., Schneider, K.S., Médard, G., Wettmarshausen, J., Dittlein, D.C., Shi, H., Gorka, O., Koenig, P.-A., Fromm, S., et al. (2016). K + Efflux-Independent NLRP3 Inflammasome Activation by Small Molecules Targeting Mitochondria. Immunity 45, 761-773.

He, Y., Hara, H., and Nuñez, G. (2016a). Mechanism and Regulation of NLRP3 Inflammasome Activation. Trends in biochemical sciences 41, 1012-1021.

He, Y., Zeng, M.Y., Yang, D., Motro, B., and Nuñez, G. (2016b). NEK7 is an essential mediator of NLRP3 activation downstream of potassium efflux. Nature 530, 354-357.

Hogquist, K.A., Nett, M.A., Unanue, E.R., and Chaplin, D.D. (1991). Interleukin 1 is processed and released during apoptosis. Proceedings of the National Academy of Sciences 88, 8485-8489.

Hornung, V., and Latz, E. (2010). Critical functions of priming and lysosomal damage for NLRP3 activation. European journal of immunology 40, 620-623.

Juliana, C., Fernandes-Alnemri, T., Kang, S., Farias, A., Qin, F., and Alnemri, E.S. (2012). Nontranscriptional priming and deubiquitination regulate NLRP3 inflammasome activation. Journal of Biological Chemistry 287, 36617-36622.

Kahlenberg, J.M., Lundberg, K.C., Kertesy, S.B., Qu, Y., and Dubyak, G.R. (2005). Potentiation of Caspase-1 Activation by the P2X7 Receptor Is Dependent on TLR Signals and Requires NF$\kappa B-D r i v e n$ Protein Synthesis. The Journal of Immunology 175, 7611-7622.

Kutner, R.H., Zhang, X.-Y., and Reiser, J. (2009). Production, concentration and titration of pseudotyped HIV-1-based lentiviral vectors. Nat Protoc 4, 495-505. 
Labun, K., Montague, T.G., Krause, M., Torres Cleuren, Y.N., Tjeldnes, H., and Valen, E. (2019). CHOPCHOP v3: expanding the CRISPR web toolbox beyond genome editing. Nucleic Acids Res.

Lin, K.-M., Hu, W., Troutman, T.D., Jennings, M., Brewer, T., Li, X., Nanda, S., Cohen, P., Thomas, J.A., and Pasare, C. (2014). IRAK-1 bypasses priming and directly links TLRs to rapid NLRP3 inflammasome activation. Proc. Natl. Acad. Sci. U.S.A. 111, 775-780.

Malireddi, R.K.S., Gurung, P., Mavuluri, J., Dasari, T.K., Klco, J.M., Chi, H., and Kanneganti, T.D. (2018). TAK1 restricts spontaneous NLRP3 activation and cell death to control myeloid proliferation. The Journal of Experimental Medicine 215, 1023-1034.

Mariathasan, S., Newton, K., Monack, D.M., Vucic, D., French, D.M., Lee, W.P., Roose-Girma, M., Erickson, S., and Dixit, V.M. (2004). Differential activation of the inflammasome by caspase1 adaptors ASC and Ipaf. Nature 430, 213-218.

Muñoz-Planillo, R., Kuffa, P., Martínez-Colón, G., Smith, B.L., Rajendiran, T.M., and Nuñez, G. (2013). K+ Efflux Is the Common Trigger of NLRP3 Inflammasome Activation by Bacterial Toxins and Particulate Matter. Immunity 38, 1142-1153.

Patel, M.N., Carroll, R.G., Galván-Peña, S., Mills, E.L., Olden, R., Triantafilou, M., Wolf, A.I., Bryant, C.E., Triantafilou, K., and Masters, S.L. (2017). Inflammasome Priming in Sterile Inflammatory Disease. Trends in molecular medicine 23, 165-180.

Rapino, F., Robles, E.F., Richter-Larrea, J.A., Kallin, E.M., Martinez-Climent, J.A., and Graf, T. (2013). $\mathrm{C} / \mathrm{EBP} \alpha$ induces highly efficient macrophage transdifferentiation of B lymphoma and leukemia cell lines and impairs their tumorigenicity. Cell reports 3, 1153-1163.

Sanjana, N.E., Shalem, O., and Zhang, F. (2014). Improved vectors and genome-wide libraries for CRISPR screening. Nat. Methods 11, 783-784.

Schmid-Burgk, J.L., Chauhan, D., Schmidt, T., Ebert, T.S., Reinhardt, J., Endl, E., and Hornung, V. (2015). A genome-wide CRISPR screen identifies NEK7 as an essential component of NLRP3 inflammasome activation. Journal of Biological Chemistry 291, jbc.C115.700492-700109.

Schmid-Burgk, J.L., Schmidt, T., Gaidt, M.M., Pelka, K., Latz, E., Ebert, T.S., and Hornung, V. (2014). OutKnocker: a web tool for rapid and simple genotyping of designer nuclease edited cell lines. Genome Res. 24, 1719-1723.

Schmidt, T., Schmid-Burgk, J.L., and Hornung, V. (2015). Synthesis of an arrayed sgRNA library targeting the human genome. Scientific Reports 5, 14987.

Sharif, H., Wang, L., Wang, W.L., Magupalli, V.G., Andreeva, L., Qiao, Q., Hauenstein, A.V., Wu, Z., Nuñez, G., Mao, Y., and Wu, H. (2019). Structural mechanism for NEK7-licensed activation of NLRP3 inflammasome. Nature 157, 1013. 
Shi, H., Wang, Y., Li, X., Zhan, X., Tang, M., Fina, M., Su, L., Pratt, D., Bu, C.H., Hildebrand, S., et al. (2016). NLRP3 activation and mitosis are mutually exclusive events coordinated by NEK7, a new inflammasome component. Nat. Immunol. 17, 250-258.

Shim, D.-W., and Lee, K.-H. (2018). Posttranslational Regulation of the NLR Family Pyrin Domain-Containing 3 Inflammasome. Frontiers in Immunology 9, 1054.

Swanson, K.V., Deng, M., and Ting, J.P.-Y. (2019). The NLRP3 inflammasome: molecular activation and regulation to therapeutics. Nat. Rev. Immunol. 29, 301.

Takata, K., Kozaki, T., Lee, C.Z.W., Thion, M.S., Otsuka, M., Lim, S., Utami, K.H., Fidan, K., Park, D.S., Malleret, B., et al. (2017). Induced-Pluripotent-Stem-Cell-Derived Primitive Macrophages Provide a Platform for Modeling Tissue-Resident Macrophage Differentiation and Function. Immunity 47, 183-198.e186.

Vande Walle, L., and Lamkanfi, M. (2016). Pyroptosis. Current biology : CB 26, R568-R572. 


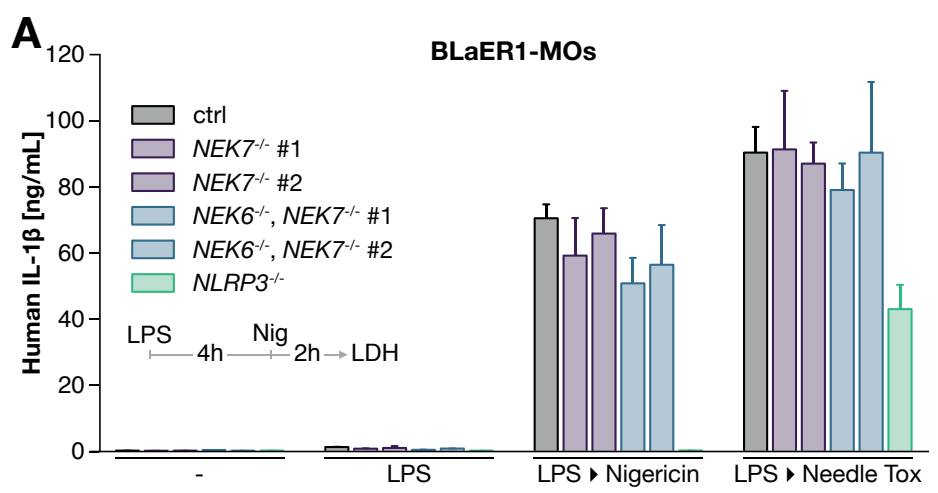

\section{B}

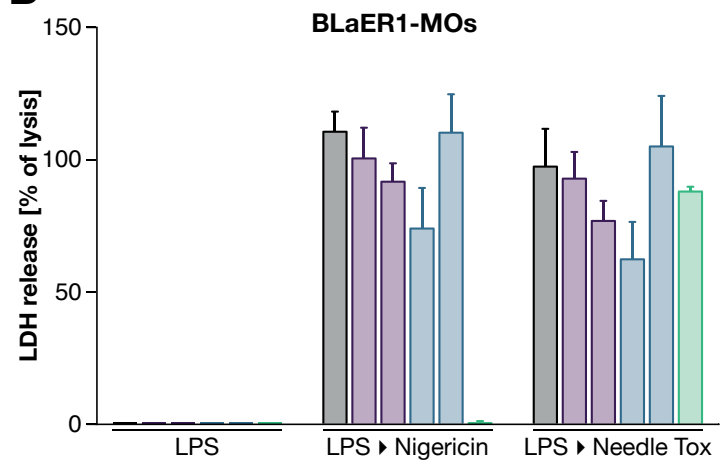

D

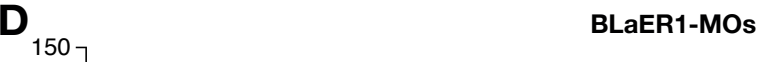

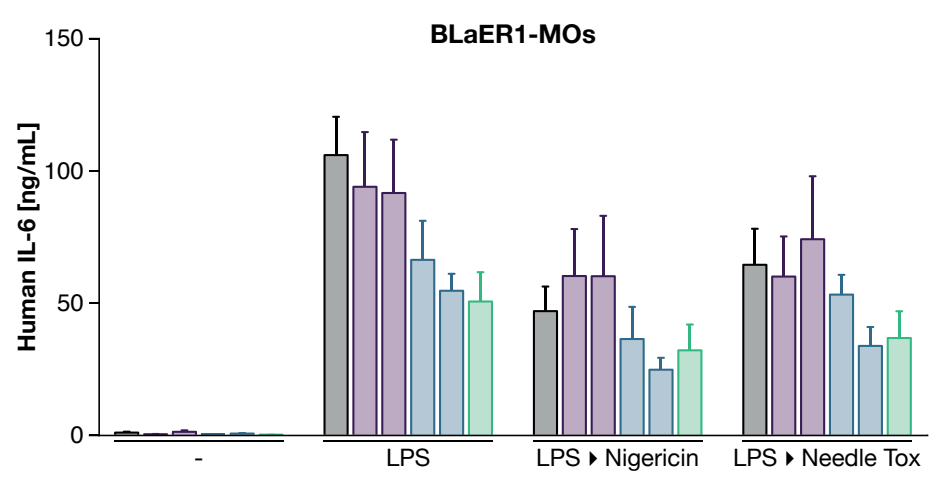

C

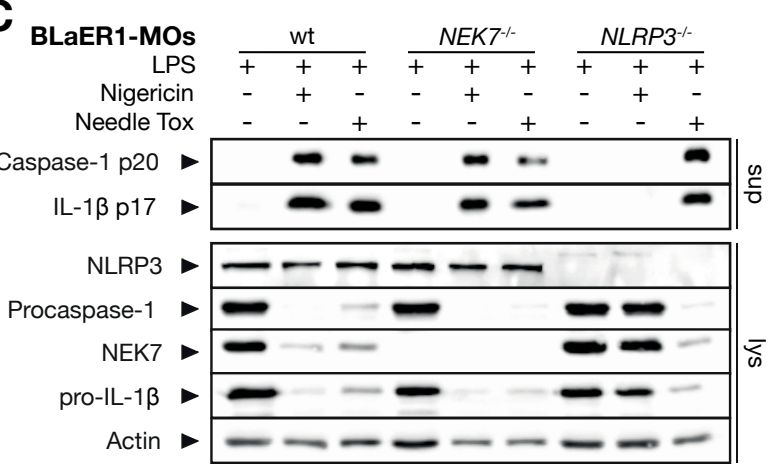

E

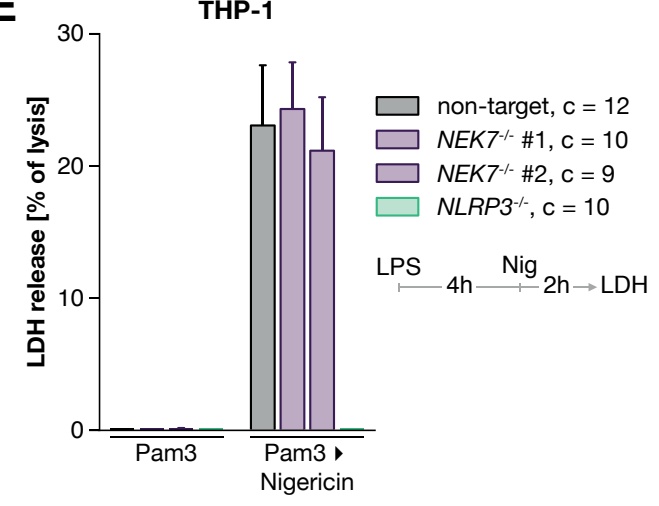

G 
A

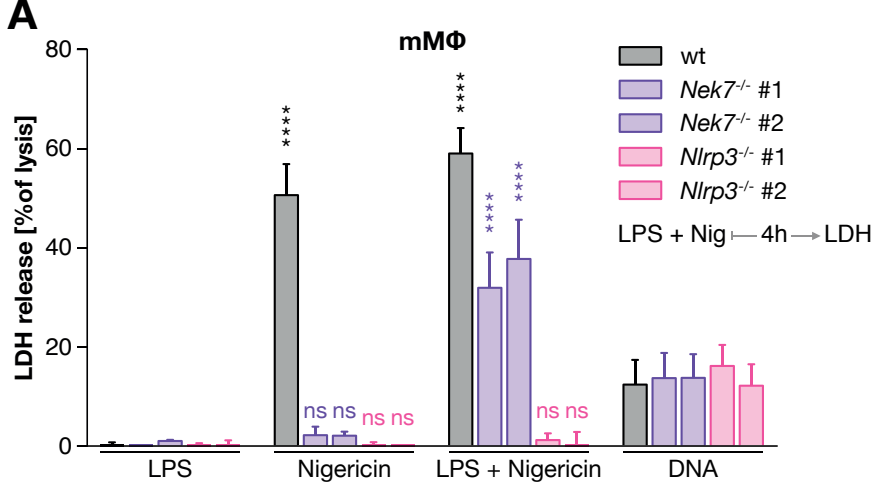

B

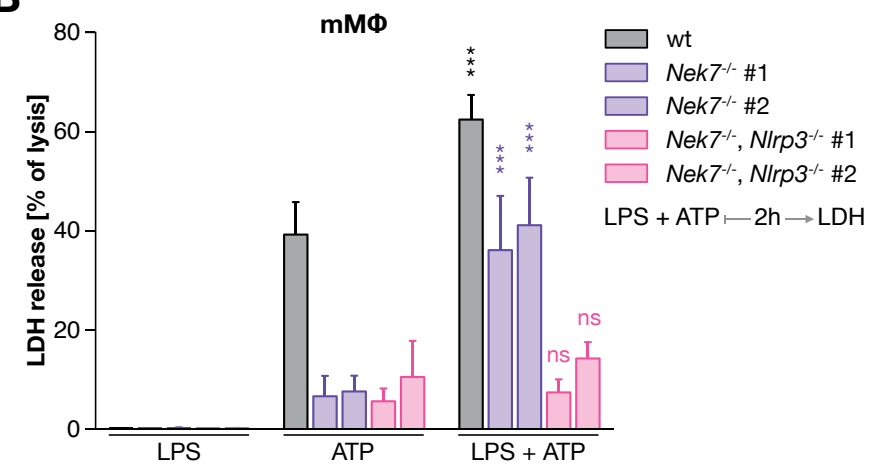

C

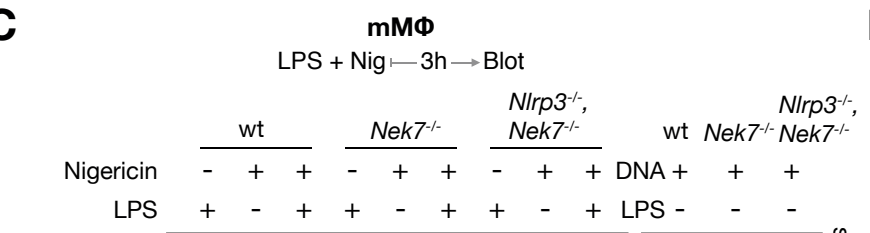

Caspase1 $\mathrm{p} 20 \longrightarrow$

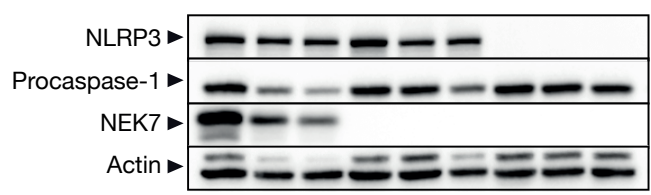

E $\mathrm{mM \Phi}$

Mouse IP-10

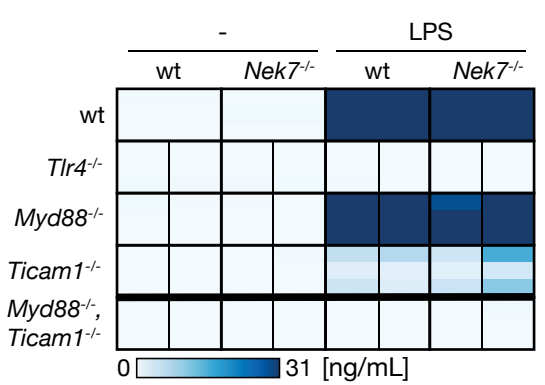

$\mathrm{mM \Phi}$

Mouse TNF

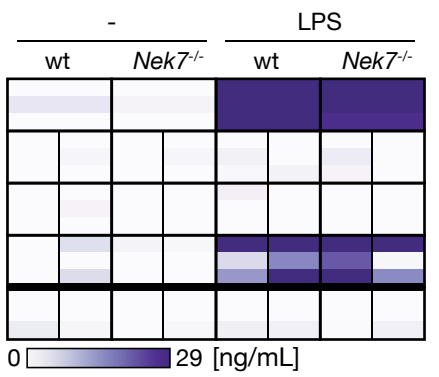

D

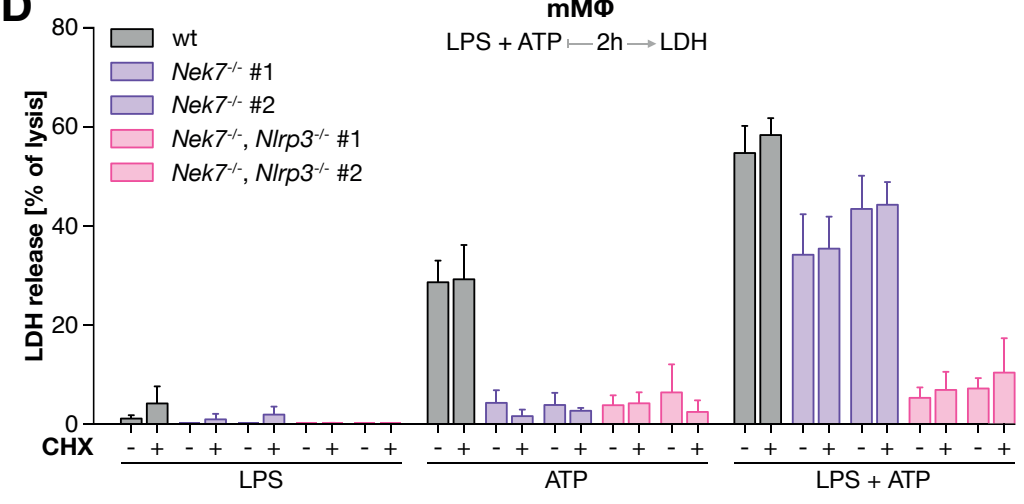

IM⿻

LDH release

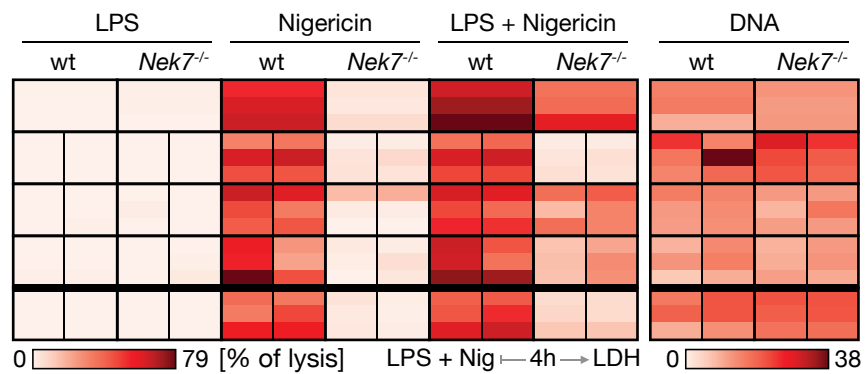

F
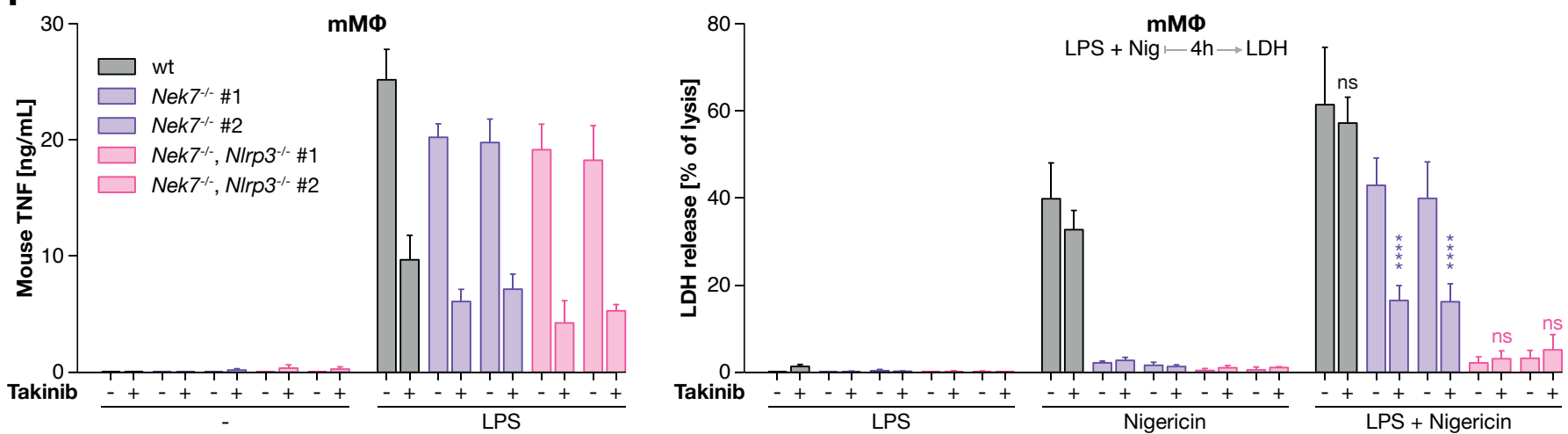

Figure 2 
A

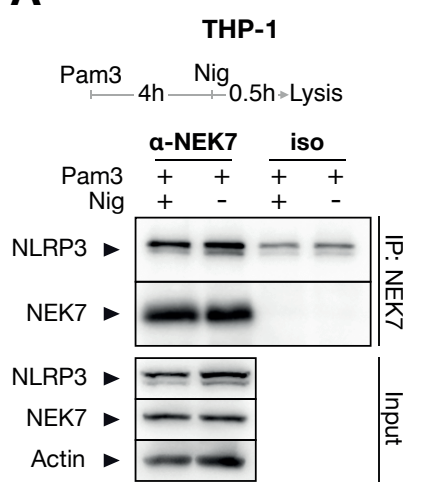

D
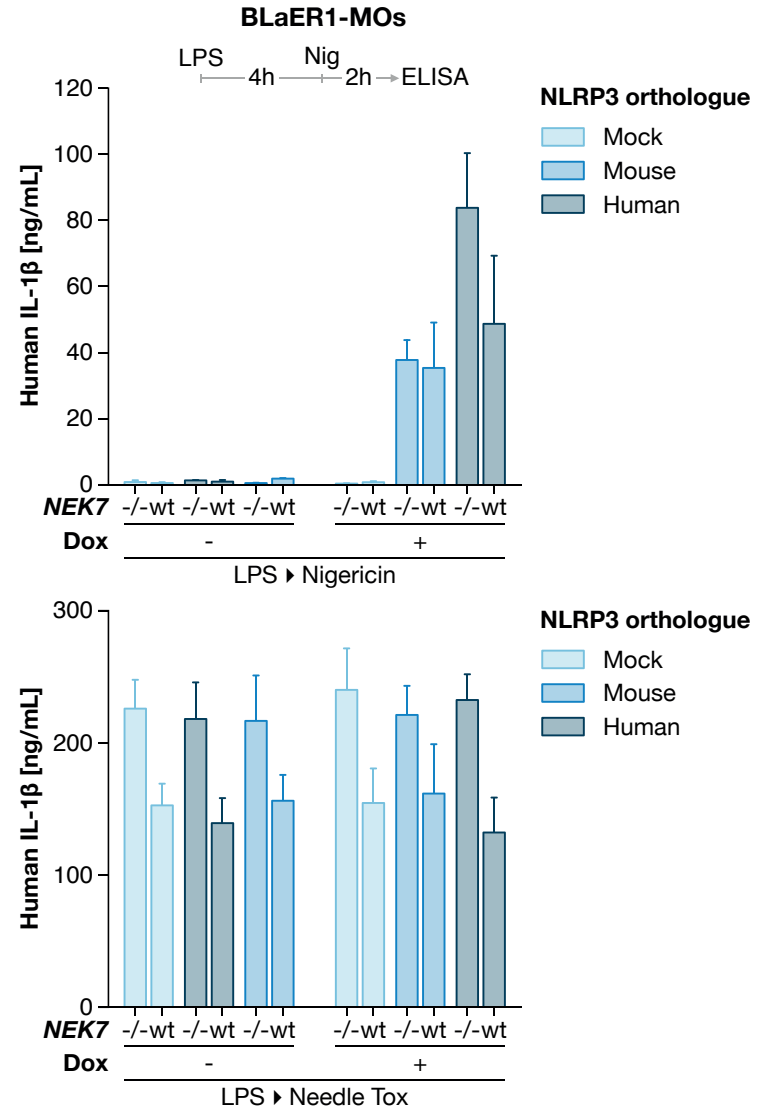

F

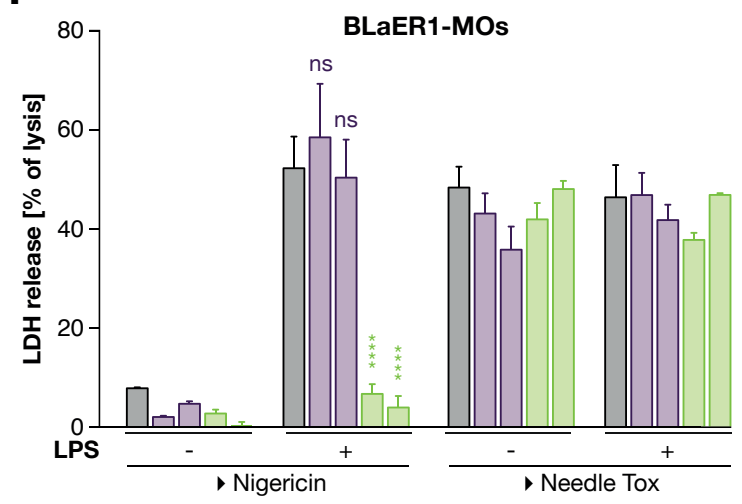

B

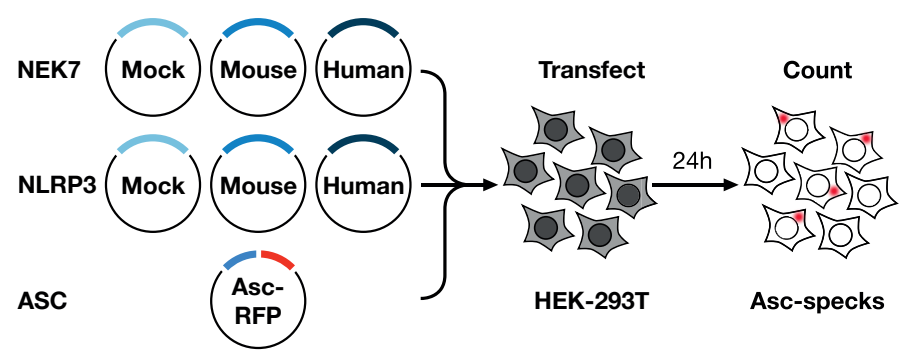

C

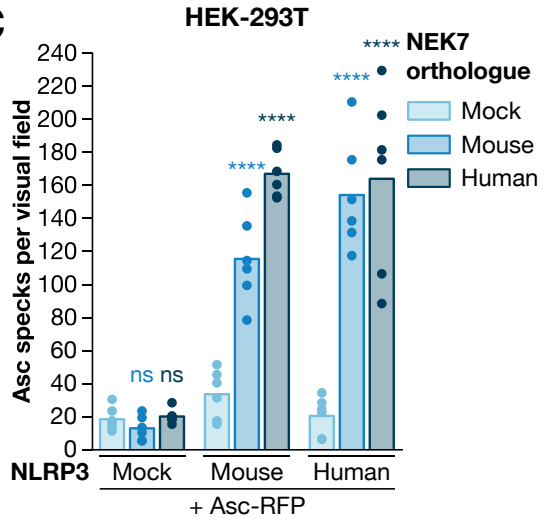

E
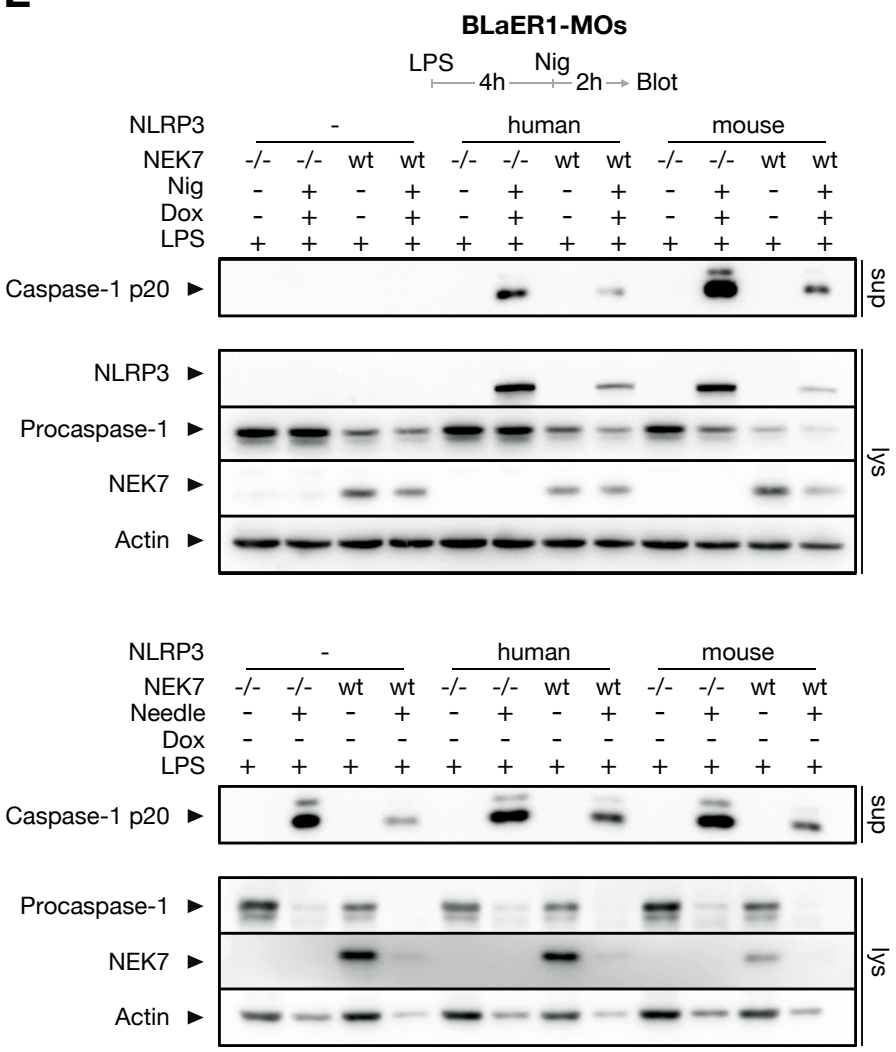

G
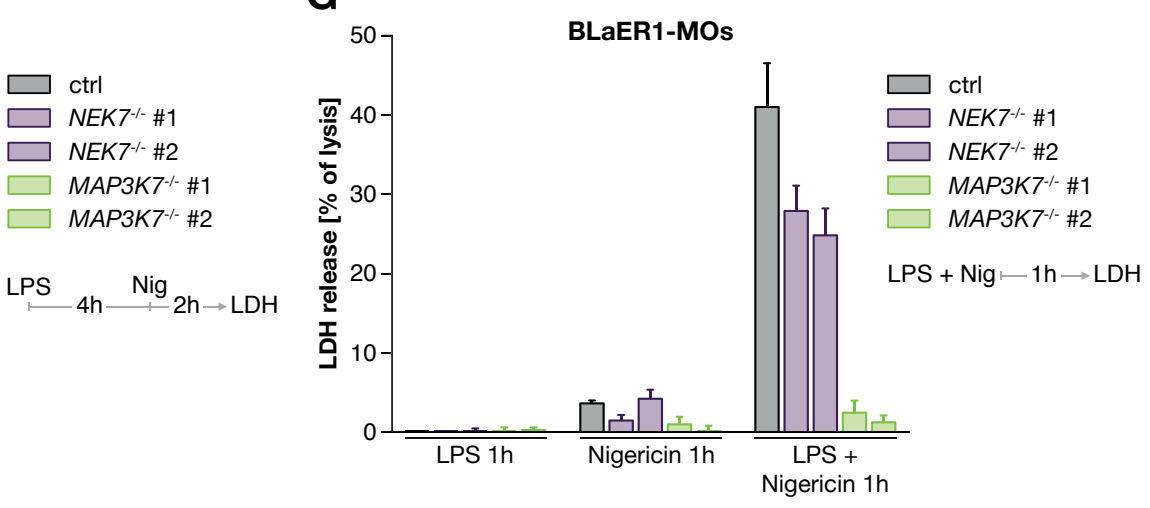


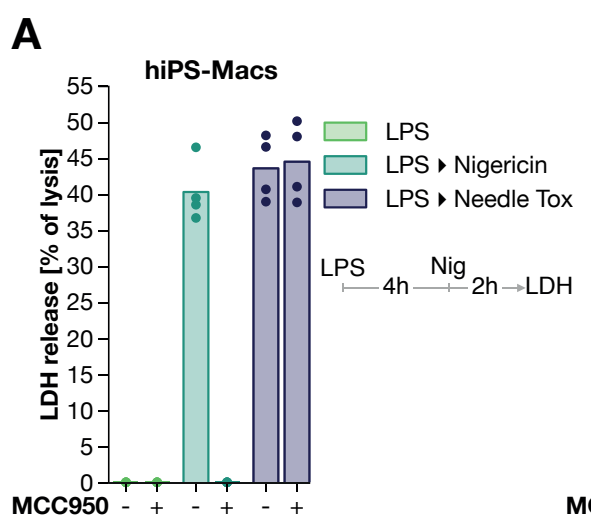

B

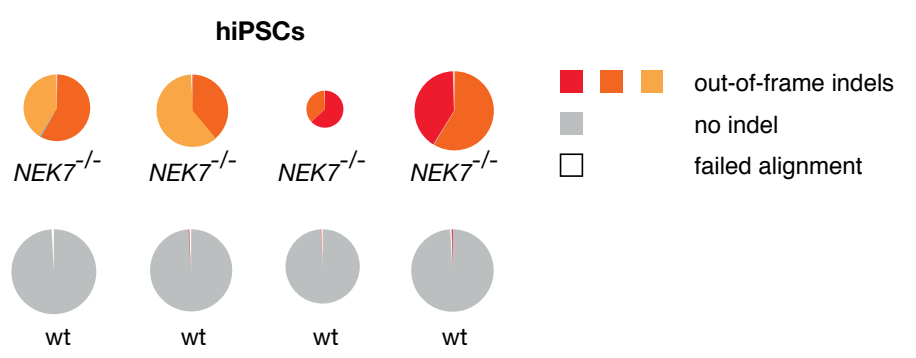

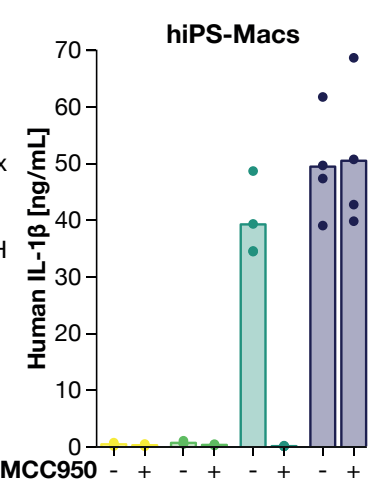

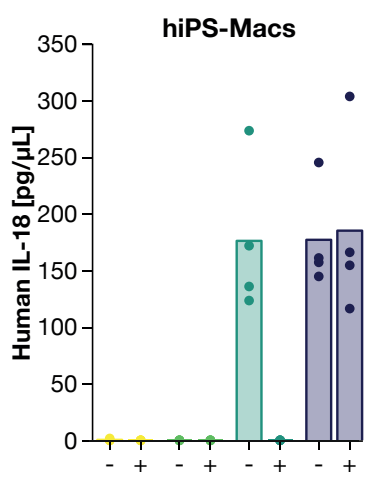

C

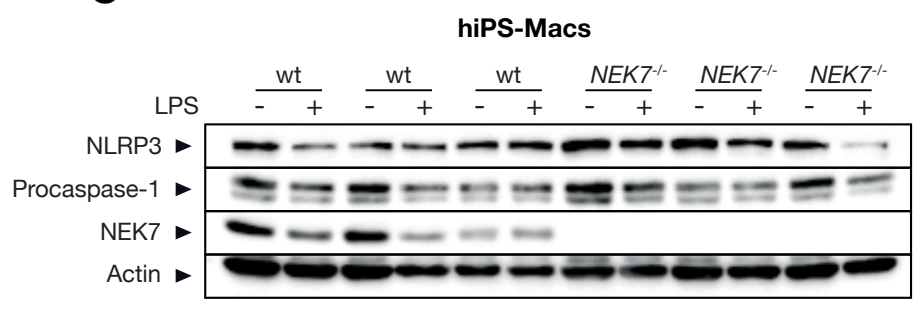

D

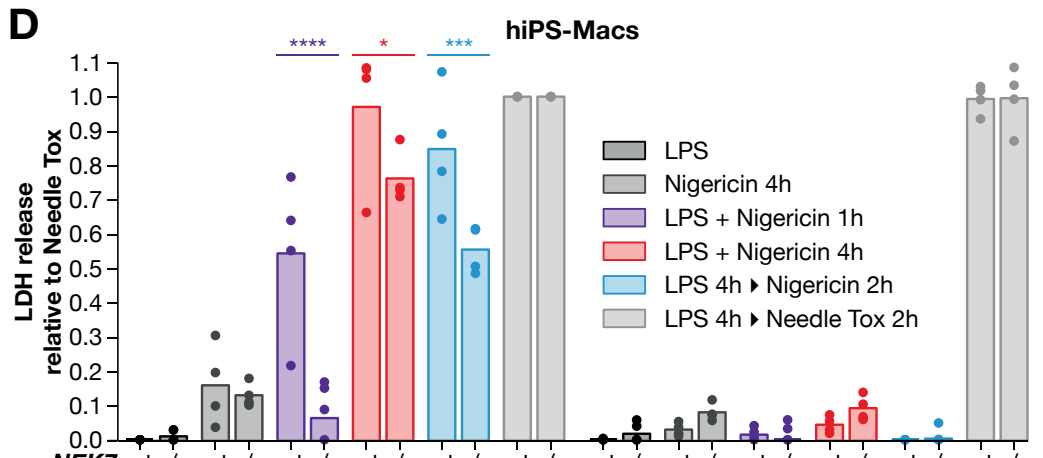

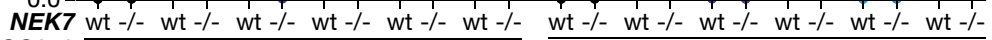
MCC950

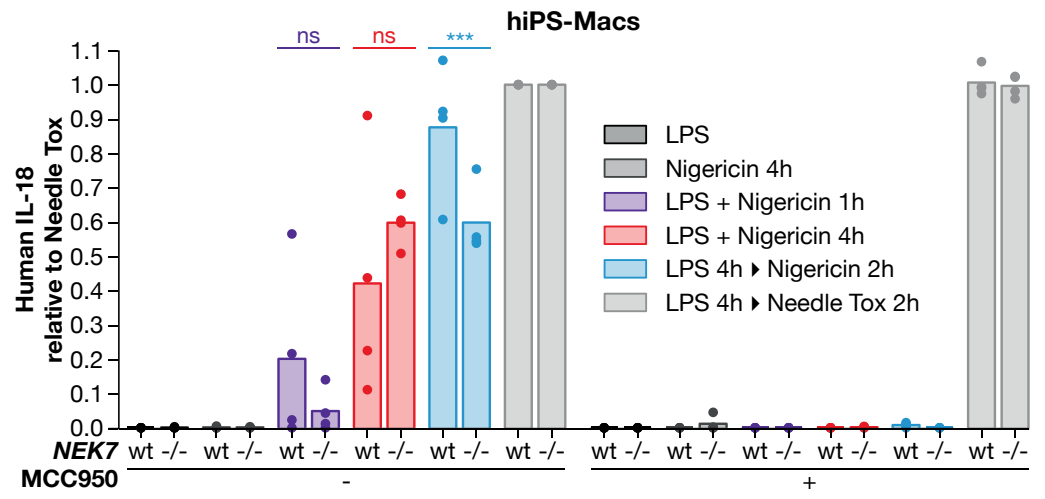

E

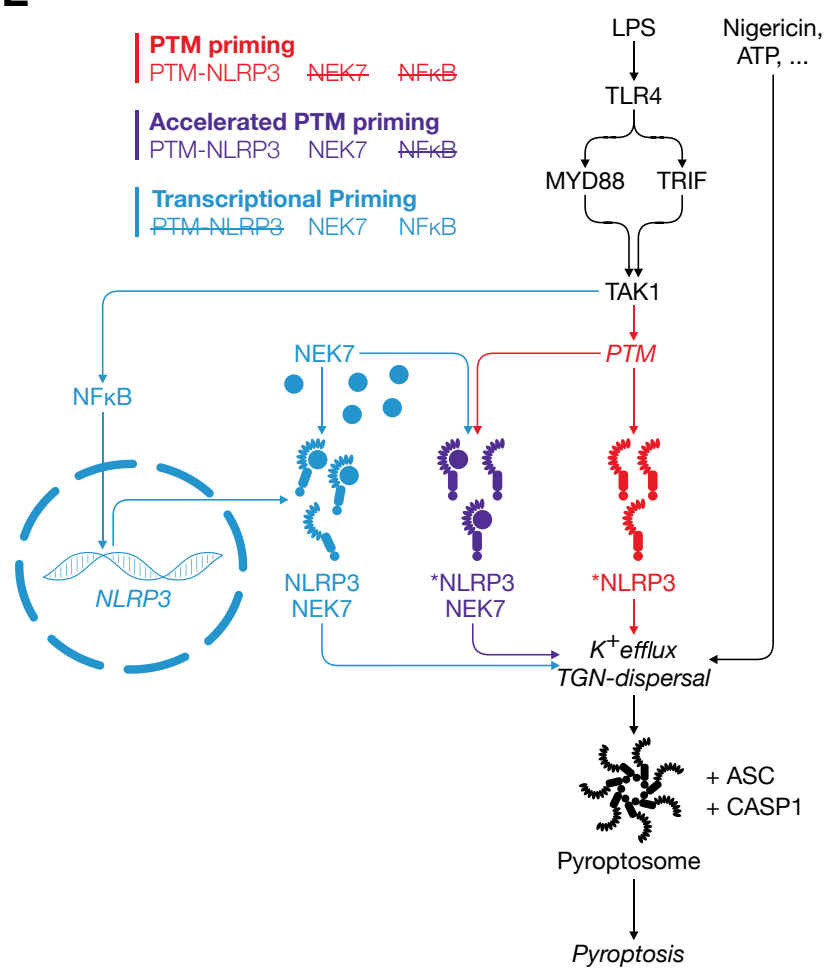




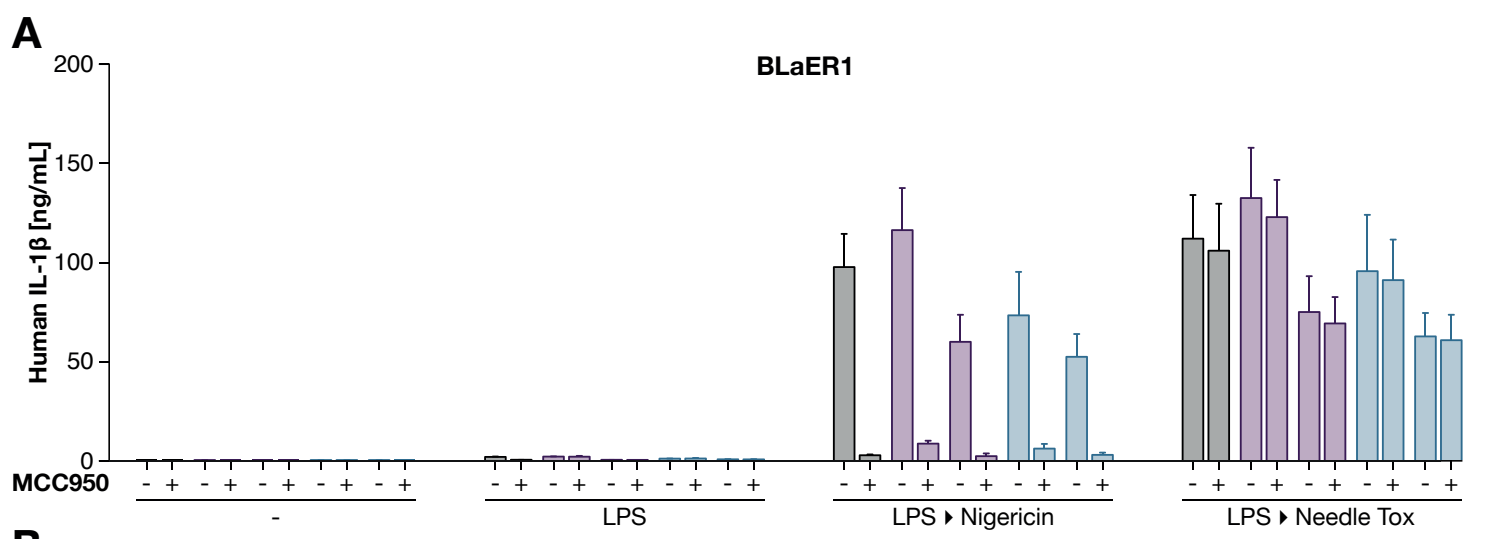

B
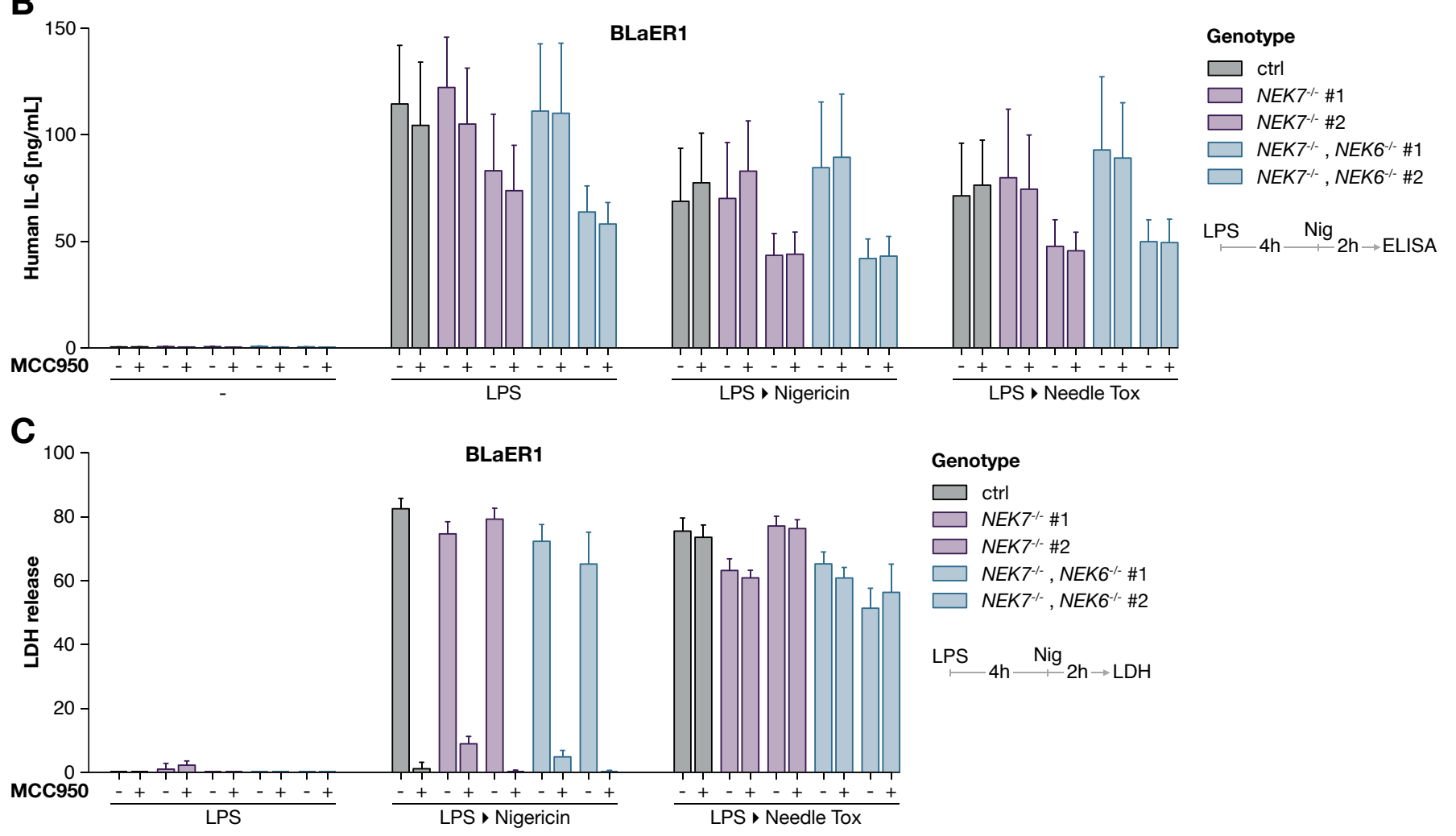

D

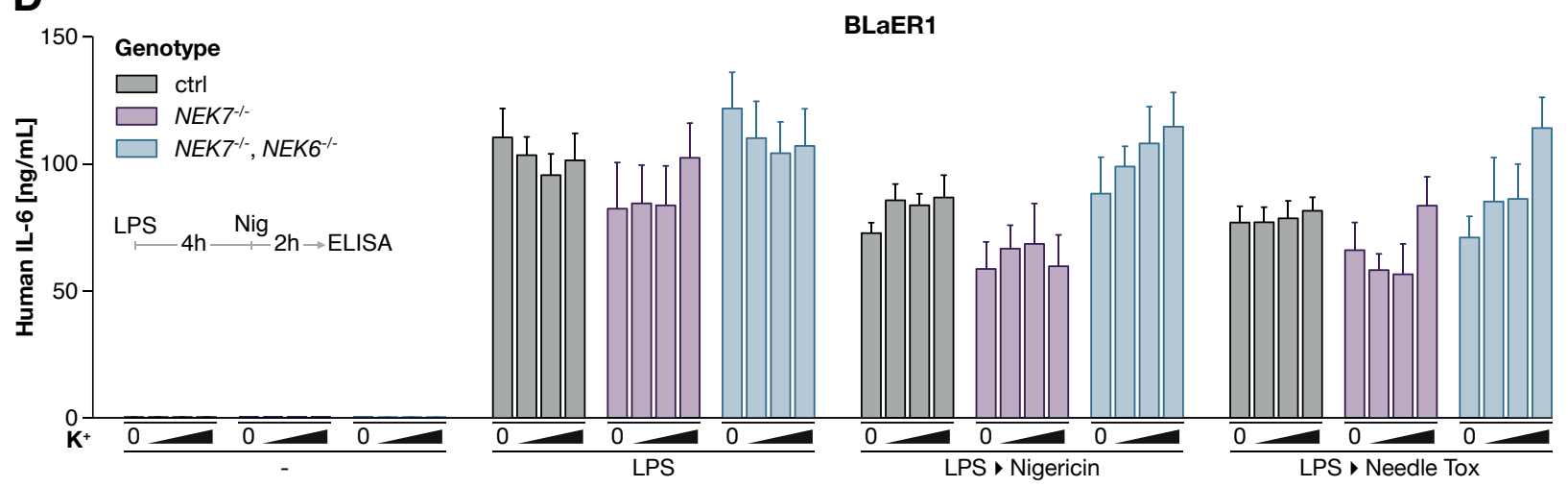


A

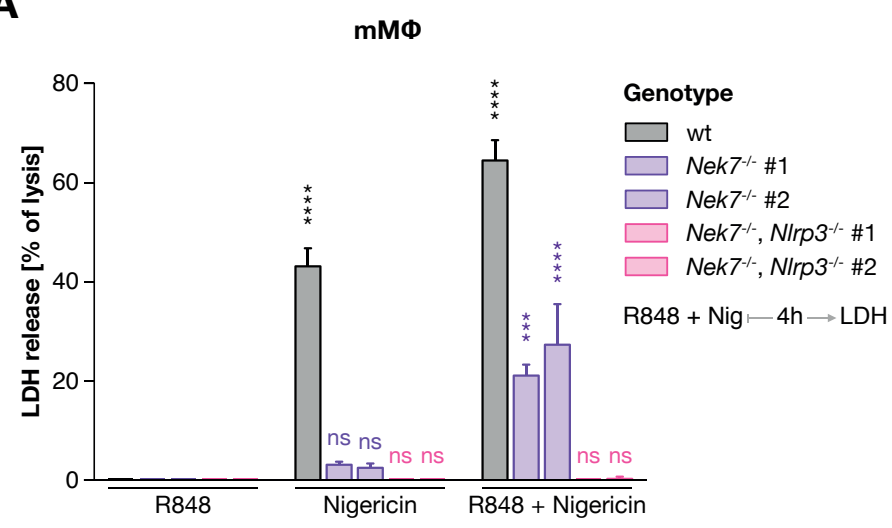

C

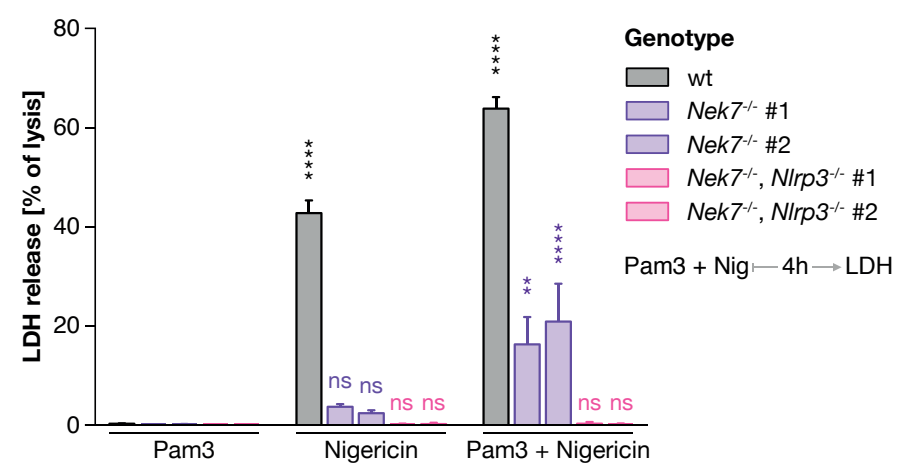

E

mMФ

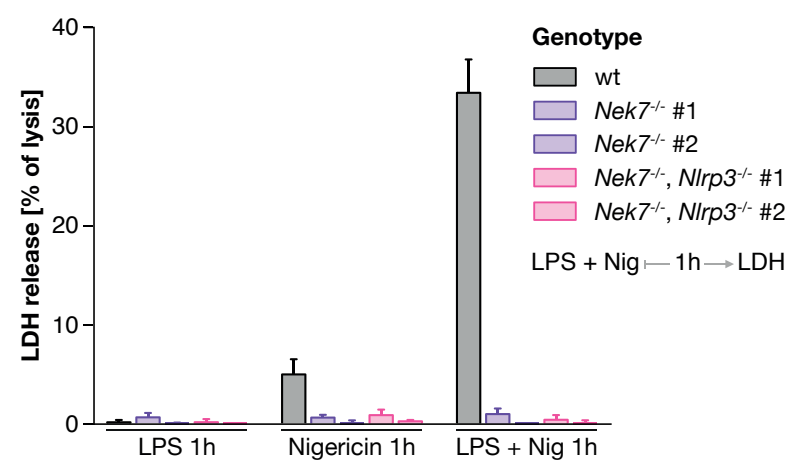

G

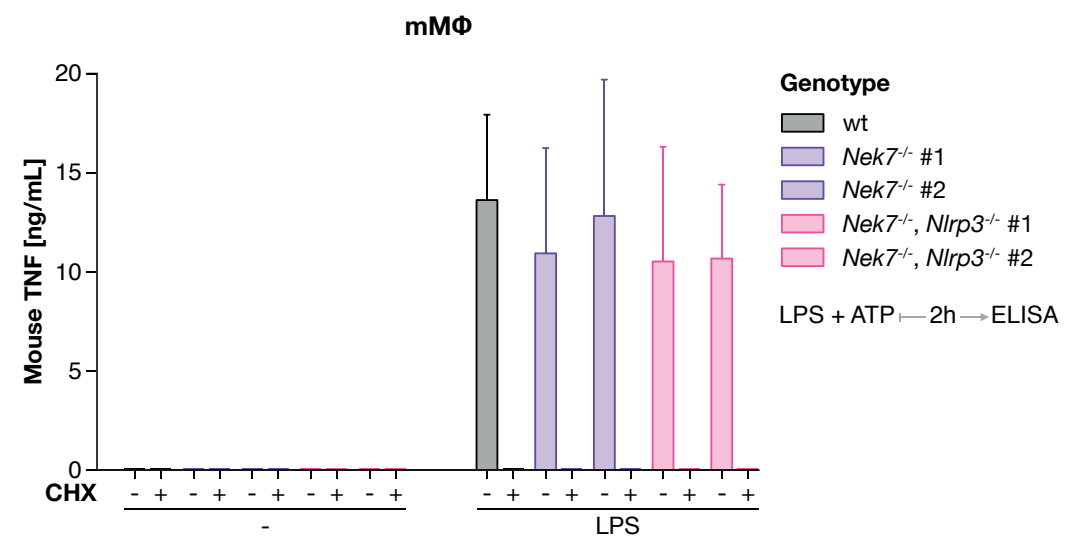

\section{B}

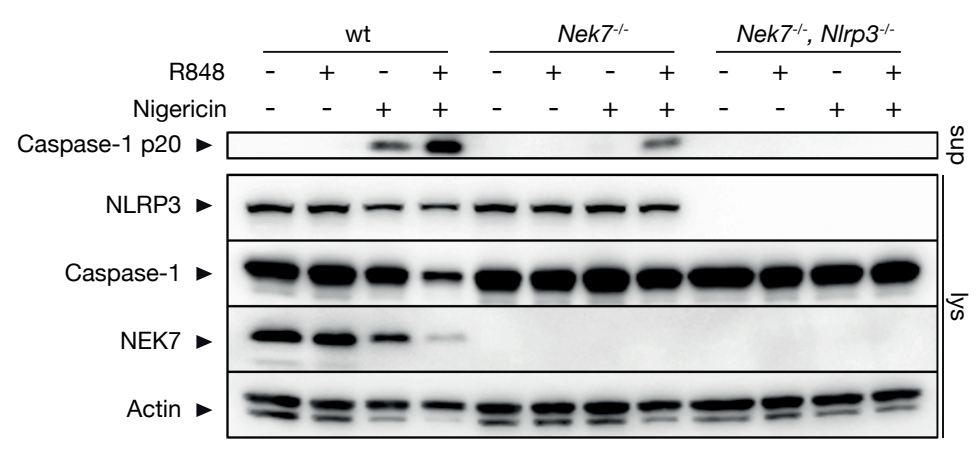

D

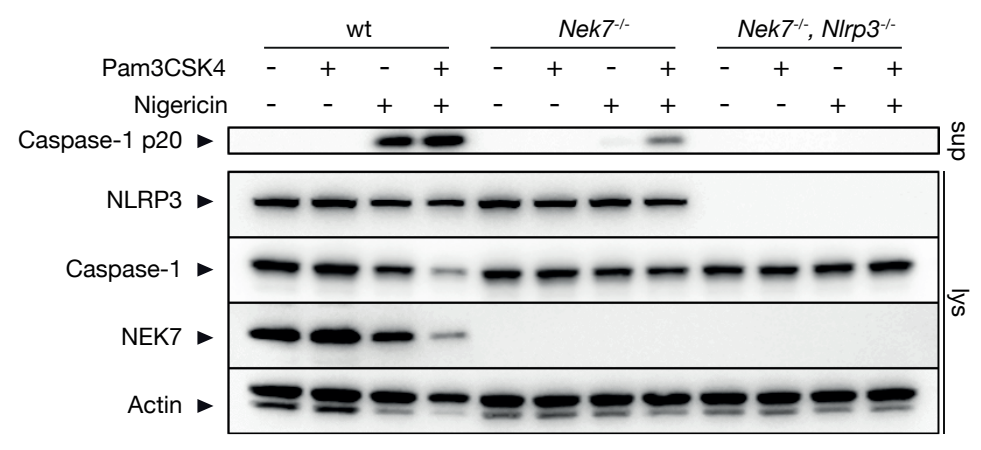

F

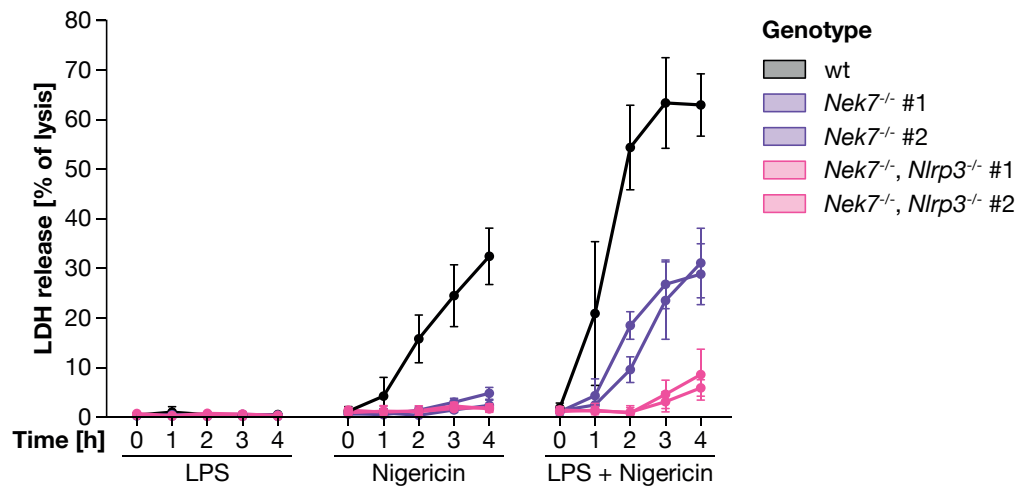


A

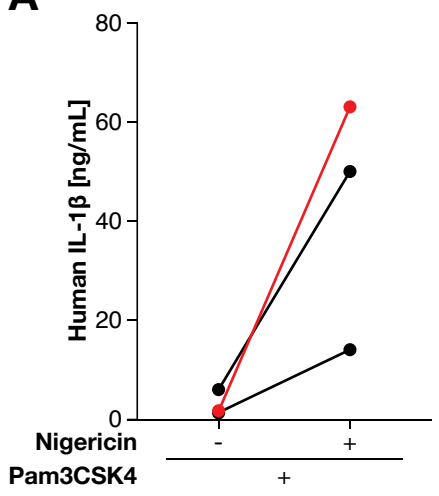

C

\section{HEK-293T}

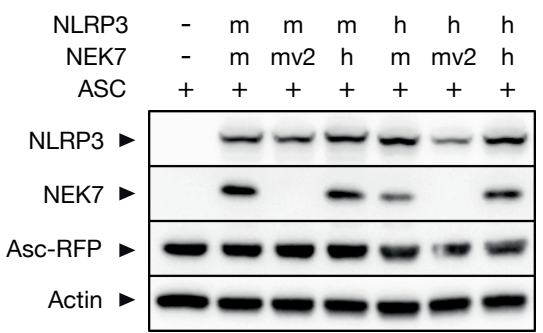

D

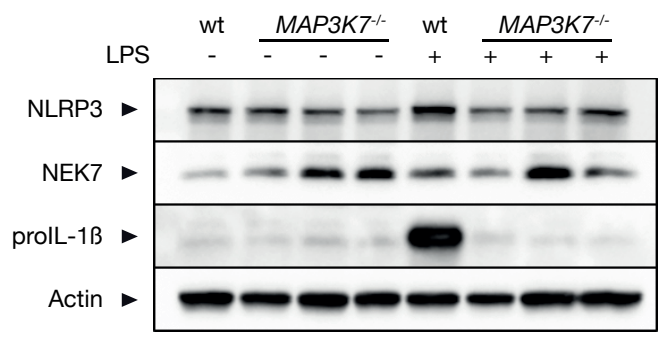

E

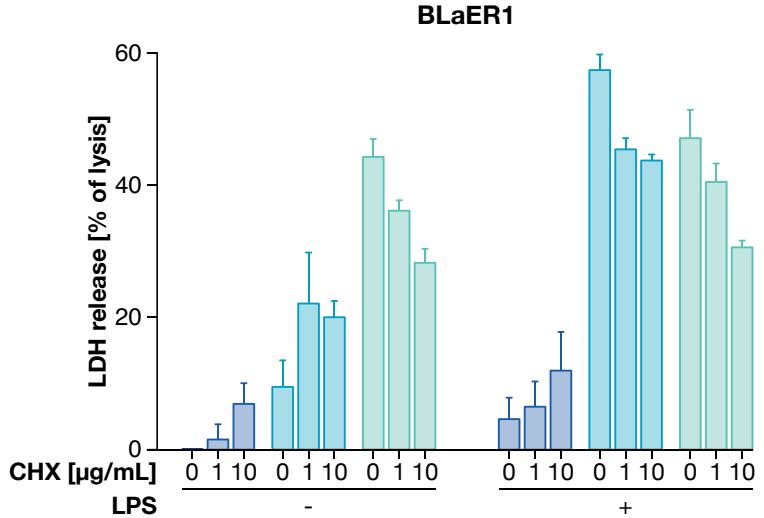

B

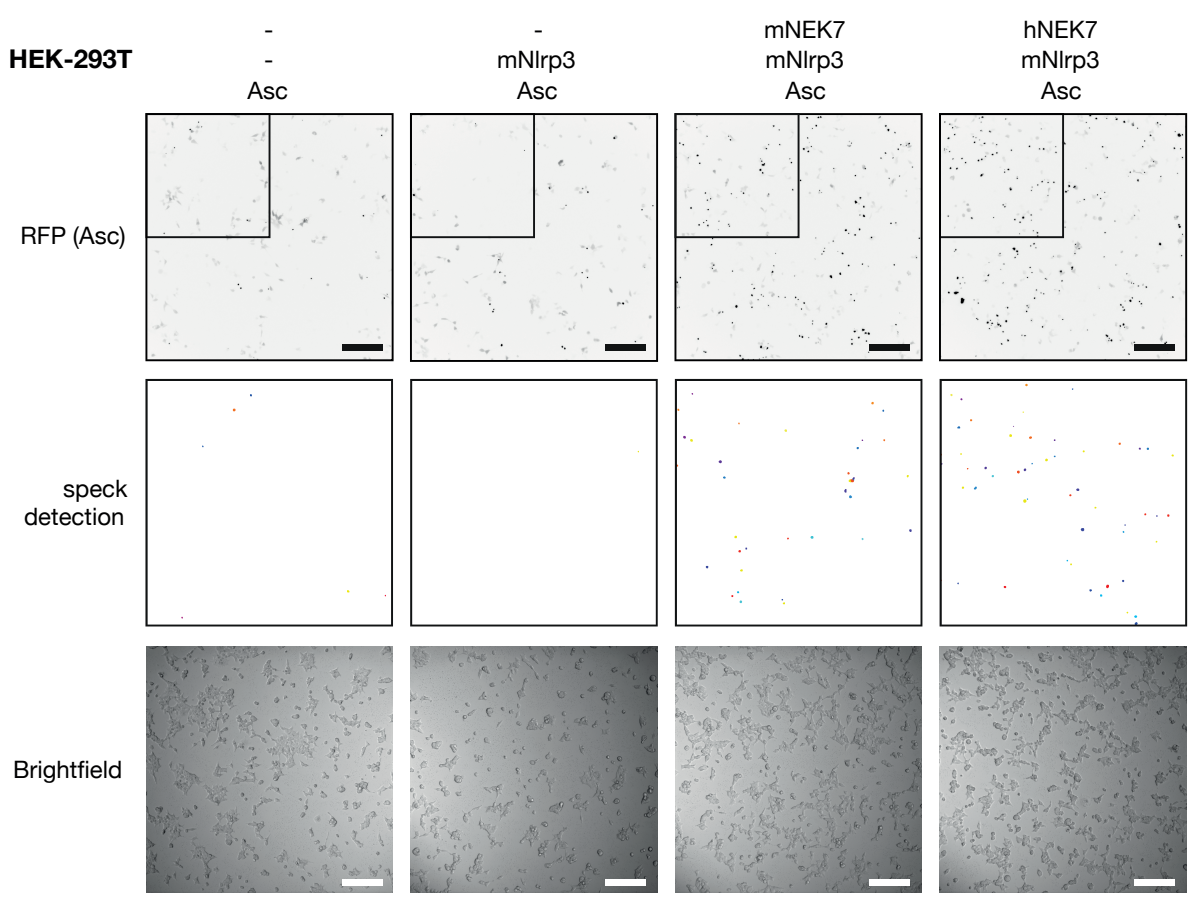

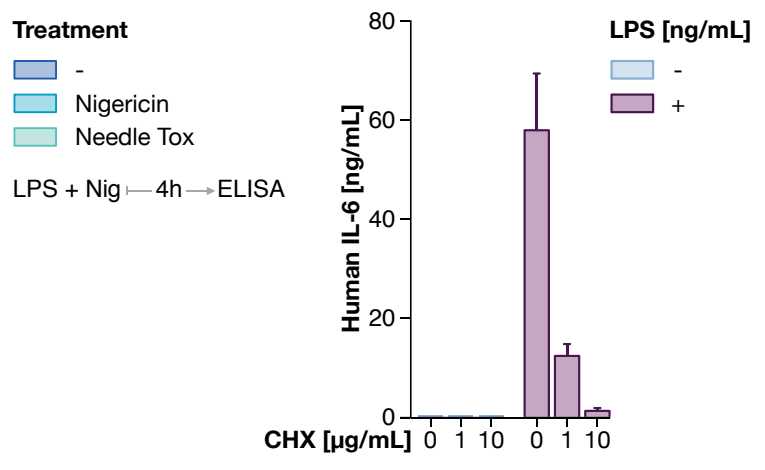


bioRxiv preprint doi: https://doi.org/10.1101/799320; this version posted October 9,2019 . The copyright holder for this preprint (which was not certified by peer review) is the author/funder. All rights reserved. No reuse allowed without permission.

A

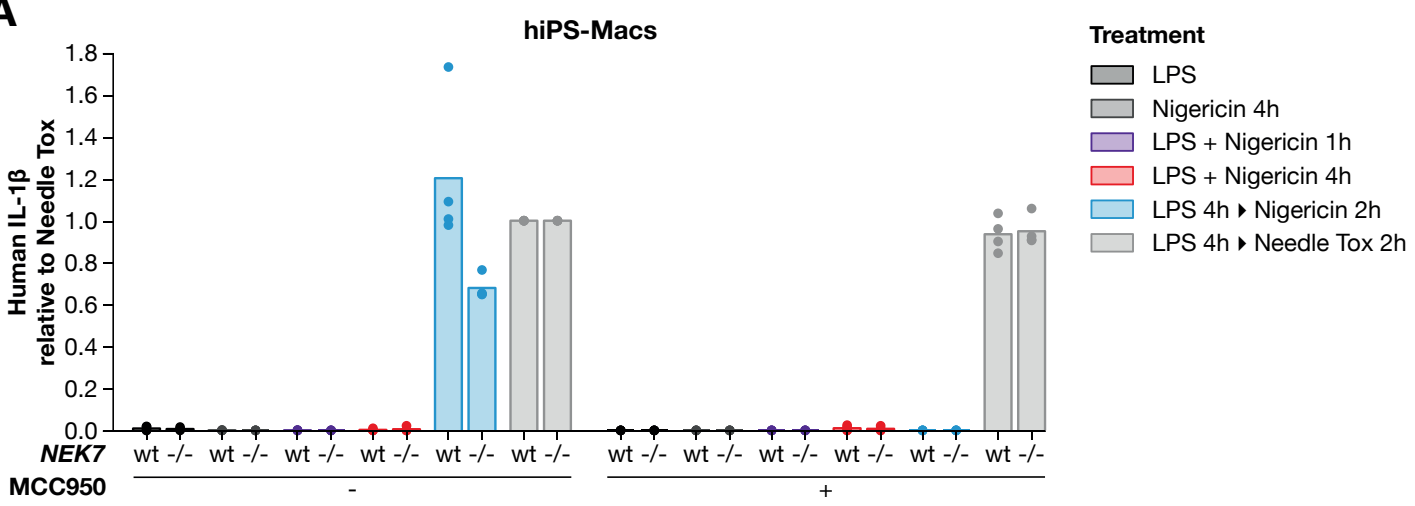

B

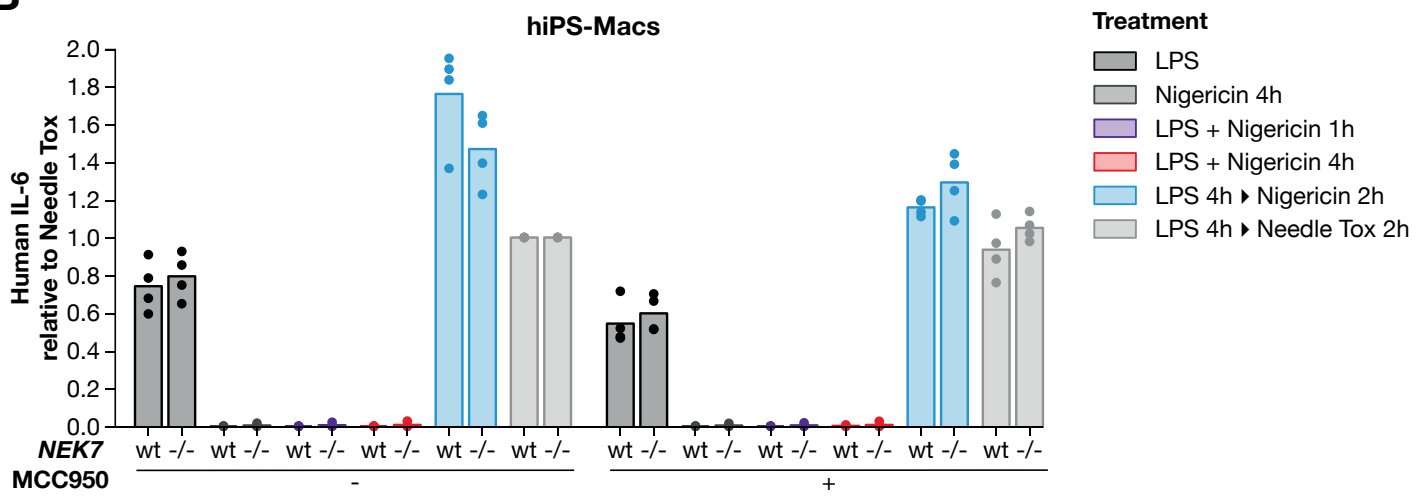

